\title{
Key Activating and Inhibitory Ligands Involved in the Mobilization of Natural Killer Cells for Cancer Immunotherapies
}

\section{Surojit Karmakar (D) \\ Pradipta Pal \\ Girdhari Lal (DD}

National Centre for Cell Science (NCCS), Pune, MH, 4I I007, India
Correspondence: Girdhari Lal National Centre for Cell Science (NCCS), NCCS Complex, Ganeshkhind, Pune, $\mathrm{MH}, 4 \mathrm{I}$ I007, India

Tel +9l-20-2570-8292

$\mathrm{Fax}+9 \mathrm{I}-20-2568-2259$

Email glal@nccs.res.in

\begin{abstract}
Natural killer (NK) cells are the most potent arm of the innate immune system and play an important role in immunity, alloimmunity, autoimmunity, and cancer. NK cells recognize "altered-self" cells due to oncogenic transformation or stress due to viral infection and target to kill them. The effector functions of NK cells depend on the interaction of the activating and inhibitory receptors on their surface with their cognate ligand expressed on the target cells. These activating and inhibitory receptors interact with major histocompatibility complex I (MHC I) expressed on the target cells and make decisions to mount an immune response. NK cell immune response includes cytolytic activity and secretion of cytokines to help with the ongoing immune response. The advancement of our knowledge on the expression of inhibitory and activating molecules led us to exploit these molecules in the treatment of cancer. This review discusses the importance of activating and inhibitory receptors on NK cells and their clinical importance in cancer immunotherapy.
\end{abstract}

Keywords: natural killer cells, innate immune system, oncogenic transformation, cancer, activating and inhibitory receptors

\section{Introduction}

Despite the rapid advancement of different therapeutic strategies, cancer is one of the most deadly diseases that affect millions of people worldwide. ${ }^{1}$ Cancer develops in a host body by damaging the cells' genetic component (mutation) beyond repair. These changes may occur spontaneously or by some agents like carcinogens or viruses. ${ }^{2}$ Such changes lead to cellular signaling abnormalities that culminate in the growth and rapid proliferation of these "altered-self" cells to form tumors. ${ }^{3}$ The host's immune system recognizes these cancer cells as a foreign entity due to the expression of neoantigens on the cell surface. ${ }^{4}$ These neoantigens are expressed on the surface of cancer cells through MHC class I molecules, taken up and processed by professional antigen-presenting cells (APCs). APCs present neoantigen to CD8 $8^{+}$ $\mathrm{T}$ cells and activate them. These activated $\mathrm{CD} 8^{+} \mathrm{T}$ cells recognize and kill the cancer cells that express MHC class I molecules loaded with neoantigen-derived peptides. ${ }^{5}$ Cancer cells can escape this immune surveillance despite these formidable defense mechanisms, develop tumors, and metastasize to distant organs. ${ }^{6}$ Various mechanisms govern these immune-escape phenomena of cancer cells, including over-expression of immune checkpoint molecules, secretion of regulatory cytokines including TGF- $\beta$, and downregulation of expression of MHC class 
I molecules on the cancer cell surface. ${ }^{7}$ When the cancer cells reduced the expression of MHC class I bound neoantigens on their surface, they were no longer recognizable by the antigen-specific $\mathrm{CD} 8^{+} \mathrm{T}$ cells. ${ }^{8}$ Natural killer cells are innate immune cells that can eliminate foreign particles, including viruses and cancer cells. NK cells recognize the absence of MHC class I molecules on cells and eliminate them. ${ }^{9,10} \mathrm{NK}$ cells express different sets of activating and inhibiting receptors on their surface. Based on the activities of these receptors, NK cells are licensed to perform their cytotoxic action. ${ }^{11}$

Currently, researchers are trying to modulate the NK cells to promote antitumor immunity by activating the activating receptor or blocking the inhibitory receptors. ${ }^{12}$ In this review, we have described the role of different activating and inhibitory receptors on antitumor functions of NK cells and how we can exploit NK cell activity to develop various therapeutic strategies to promote the antitumor function of NK cells.

\section{NK Cell Biology - A Brief Overview Development, Classification, and Memory of NK Cells}

NK cells are innate lymphoid cells that show potent cytotoxic potential against virus-infected cells or alteredself cells like tumor cells. ${ }^{13}$ In peripheral blood, mature NK cells lack expression of $\mathrm{T}$ cell receptors (TCR) and CD3 molecules. ${ }^{14}$ In humans, the presence of the neural cell-adhesion molecule (NCAM or CD56) identifies mature NK cells, which is absent in mice. ${ }^{15} \mathrm{NK}$ cells in C57BL/6 and NZB mice express NK1.1 molecule (also known as CD161; Killer cell lectin-like receptor subfamily B, member 1, KLRB1), but other mice strains (such as $\mathrm{BALB} / \mathrm{c}, \mathrm{SJL}, \mathrm{AKR}, \mathrm{CBA}$, and $\mathrm{C} 3 \mathrm{H}$ ) lack the expression of this molecules. The majority of NK cells in all the strains of mice can be identified using monoclonal antibody DX5. NK cells develop from $\mathrm{CD} 34^{+}$hematopoietic stem cells known as common lymphoid progenitor cells (CLPs) in the bone marrow. CLPs originate in the bone marrow. ${ }^{16}$ They mature in the primary and secondary lymphoid organs and can persist in the periphery for longer time. ${ }^{16}$ These NK cells have cytotoxic or regulatory phenotypes depending on the expression of various activating and inhibiting receptors on their surface and interaction with their cognate ligands. ${ }^{17}$ The expression of various surface molecules and their interaction with the surroundings classifies human NK cells into different functional subsets. $\mathrm{CD} 11 \mathrm{~b}^{+} \mathrm{CD} 27^{-} \mathrm{CD} 56^{\mathrm{dim}} \mathrm{NK}$ cells show a potent cytotoxic function. These cells also express several activating receptors on their surface, thus exhibiting potent activating signals. $\mathrm{CD} 11 \mathrm{~b}^{-} \mathrm{CD} 27^{-} \mathrm{CD} 56^{\text {bright }}$ NK cells show a tolerogenic function and show inhibitory receptor expression. $\mathrm{CD} 11 \mathrm{~b}^{ \pm} \mathrm{CD} 27^{+} \mathrm{CD} 56^{\text {bright }} \mathrm{NK}$ cells perform various regulatory functions and are widely distributed in various organs, including the liver and uterus. ${ }^{18-20}$ Unlike $\mathrm{CD}^{+}$or $\mathrm{CD} 8^{+} \mathrm{T}$ cells, NK cells are also reported to show immunological memory. It has been shown that following mouse-cytomegalovirus (MCMV) virus infection, NK cells can show long-lived selfrenewing antigen-specific memory phenotype and respond to recall response. ${ }^{21,22} \mathrm{NK}$ cell memory response is discussed elsewhere ${ }^{23-25}$ and beyond the scope of this review.

\section{Licensing, Activation, and Function of NK Cells}

NK cell activation and function depend on their engagement with different sets of activating and inhibitory receptors with their ligands. ${ }^{26}$ Based on the type of receptor engagement, NK cells decide whether to kill or not to kill the target cells. ${ }^{27}$ The primary signal for NK cell-mediated killing is triggered by the absence of MHC class I molecules on the surface of the target cells. ${ }^{28}$ The killer cell immunoglobulin-like receptors (KIRs) recognize and bind to MHC class I molecules. The downstream signaling from KIRs suppresses the activation and subsequent cytotoxic killing of target cells. During the development of NK cells, the exposure of KIRs to self MHC molecules governs NK cell maturation and provides tolerance to the destruction of self-cells by NK cells. This complex process is called the "licensing" of NK cells. ${ }^{29}$ The number of MHC class I molecules on the target cells dictates the strength of cytotoxicity by NK cells. In mature NK cells, the KIR-mediated inhibition is not an absolute phenomenon. One or more strong activating stimuli can reverse this inhibition. ${ }^{30}$

In addition, another mechanism of NK cell-mediated killing is antibody-dependent cellular cytotoxicity (ADCC). ${ }^{31}$ In this process, the CD16 receptor (Fc $\gamma$ RIIIA) on the NK cell surface recognizes the $\mathrm{Fc}$ regions of immunoglobulin ${ }^{32}$ and targets to kill immunoglobulincoated opsonized target cells. ${ }^{32}$ Various cytokines are also known to govern the NK cell cytotoxicity. ${ }^{30}$ IL-2 and IL-15 activate NK cells and promote their survival 
and proliferation. ${ }^{33}$ IL-12 and IL-18 also activate NK cells and are potent inducers of IFN- $\gamma$ production by NK cells. ${ }^{34}$

Once NK cells are activated and licensed to kill the target cells, they kill them in two ways. Either they are directly lysing the cells by releasing perforin or granzyme in the vicinity of the target cells or by receptor-induced target cell apoptosis. During NK cell degranulation, lysosomal-associated membrane protein-1 (LAMP-1 or CD107a) and -2 (LAMP-2 or CD107b) transiently appear on the NK cell surface. The expression of LAMP-1 on the NK cells is a marker for indirect measurement of NK cell cytotoxicity. ${ }^{35}$ Perforin produces pore in the target cell, and then granzyme enters the cell and destroys the target cells. $^{27,36,37} \mathrm{NK}$ cells also express TNF receptor ligands which include FasL, TRAIL-L, and TNFR. ${ }^{38}$ Interaction of these ligands present on NK cells with their cognate receptor on target cells induces apoptosis of the target cells. $^{39,40}$ The development, licensing, activation, and cytotoxic function of NK cells ultimately depends on the interaction between activating and inhibitory receptors on NK cells and their ligands on target cells. In the next section, we have described various activating and inhibitory receptors on NK cells and their role in antitumor immunity.

\section{Activating Receptors on NK Cells and Their Role in Antitumor Immunity}

NK cells contain an extensive repertoire of activating and inhibitory receptors (Table 1). These germline-encoded receptors do not require "V(D)J" recombination for their diversity and functions. When these receptors interact with their ligands, they transmit either stimulatory or inhibitory signals to NK cells. In addition to this signal, the interaction of activating receptors on NK cells and their cognate ligand on the target surface is essential for optimum activation and cytolytic capacity of NK cells. The intracellular domain of the activating receptor contains immunoreceptor tyrosinebased activation motifs (ITAMs). Interaction of activating receptor-ligand complexes leads to phosphorylation of ITAM by the Src family of tyrosine kinases such as Lck, Fyn, Src, Yes, Fgr, and Lyn (Figure 1). These signaling pathways directly activate the mitogen-activated protein kinase (MAPK) and extracellular signal-regulated kinase (ERK) pathway. ${ }^{41}$ This signaling culminates in elevated intracellular $\mathrm{Ca}^{2+}$ levels and actin cytoskeleton rearrangement, promoting the release of cytotoxic granules and the killing of target cells.
NK group 2 calcium-dependent lectin-like family of receptors performs both activating and inhibitory functions on NK cells. Among them, NKG2D has a stimulatory role on NK cell activity. Apart from NK cells, NK T cells, $\mathrm{CD}^{+}$and $\mathrm{CD}^{+} \mathrm{T}$ cells, and $\gamma \delta \mathrm{T}$ cells also express NKG2D. In mice, NKG2D interacts with retinoic acid early inducible-1 family of proteins (Rae-1 $\alpha-\varepsilon)$, murine UL16-binding protein-like transcript 1 (MULT1), and H60 group of proteins (H60a, H60b, H60c). ${ }^{42}$ In humans, NKG2D recognizes $\mathrm{MHC}$ class I chain-related protein A (MICA) and $\mathrm{B}$ (MICB) and UL16-binding proteins (ULBP1-6). MICA/B was found to be expressed in cancer with epithelial origin ${ }^{43-45}$ but less expressed on hematological malignancies. ${ }^{46-49}$ In contrast, expression of ULBPs is predominantly known on leukemia ${ }^{49,50}$ but relatively rare in solid cancers. The expression of Rae-1 and MULT1 is variable in different forms of cancers. ${ }^{51-54}$ The broad expression of NKG2D ligands makes them a suitable target for developing many forms of NK-based antitumor therapy, which we have discussed in the later sections.

Ly49 group of genes is highly polymorphic and analog to the human KIRs. They follow two nomenclature systems Ly49 and Killer Cell Lectin-like Receptor subfamily A (KLRA). ${ }^{55}$ Most of the Ly49 group of receptors (Ly49A, Ly49B, Ly49C, Ly49E, Ly49F, Ly59G, Ly49I, and Ly490) are inhibitory, and some receptors (Ly49B, Ly49D, Ly48H Ly49P, Ly49R, and Ly49W) exhibit activation functions in mice. ${ }^{55}$ They are associated with DAP12 adapter molecules and transduce signals through ITAMs. Ly49H binds to the glycoprotein m157 protein of murine cytomegalovirus (MCMV), responsible for the resistance to MCMV infection. ${ }^{56}$ Other Ly49 activating receptors such as Ly49D, Ly49P, and Ly49W recognizes $\mathrm{H}-2 \mathrm{D}^{\mathrm{d}}$ in mice. ${ }^{57-59}$ Ly49D engagement on T lymphocyte through MHC class I ligand expressed on target cells and known to promote CD4 and CD8 T cells functions and their cytotoxic potential. ${ }^{60} \mathrm{NK}$ cells also recognize $\mathrm{MHC}$ molecules on the tumor cells through Ly49D and involve in tumor rejection. ${ }^{61}$ The few subtypes of the killer cell immunoglobulin-like receptors (KIRs) family, which are activating in nature, mostly HLA-specific activating receptors, are associated with DAP12 adapter protein for their signal transduction. ${ }^{62}$

The 2B4 receptor (CD244) is a group of molecules that act as both activating and inhibitory receptors. Though it is inhibitory in mice, ${ }^{63,64}$ in humans, the expression of CD244 ligand (CD48) on the target cells enhances NK 


\begin{tabular}{|c|c|c|c|c|c|c|c|c|c|c|c|c|c|c|c|c|}
\hline 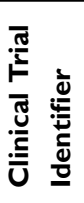 & , & ' & 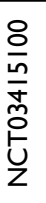 & , & & ' & 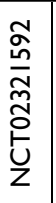 & 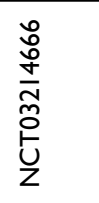 & $\begin{array}{l}\text { ồ } \\
\hat{O} \\
\frac{m}{0} \\
\text { Ũ } \\
z\end{array}$ & $\begin{array}{l}\frac{0}{N} \\
\frac{a}{y} \\
\frac{0}{0} \\
\frac{U}{Z}\end{array}$ & ' & 1 & 1 & ' & 1 & 1 \\
\hline 䲶 & d & 它 & 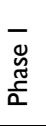 & 它 & & 总 & $\begin{array}{l}\overline{0} \\
\bar{y} \\
\frac{c}{\alpha} \\
\frac{c}{2}\end{array}$ & $\begin{array}{l}\overline{\overline{0}} \\
\bar{g} \\
\overline{\frac{\sigma}{\alpha}}\end{array}$ & $\begin{array}{l}\bar{\delta} \\
\substack{g \\
\frac{g}{\alpha}}\end{array}$ & 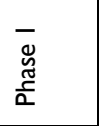 & d. & 1 & 1 & d. & I & I \\
\hline 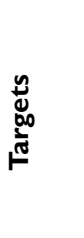 & $\begin{array}{l}\text { Oิ } \\
\text { ত̃ } \\
\stackrel{y}{z} \\
\frac{1}{\bar{U}}\end{array}$ & 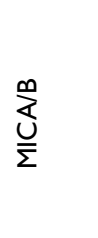 & 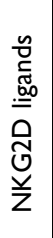 & 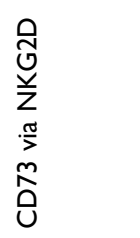 & 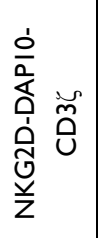 & $\begin{array}{l}\text { U్ } \\
\text { V̌ }\end{array}$ & 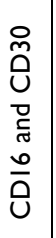 & 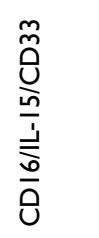 & $\frac{\varrho}{\sigma}$ & $\frac{\varrho}{\sigma}$ & 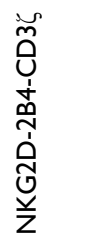 & 1 & । & 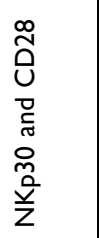 & 1 & I \\
\hline 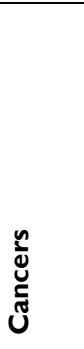 & 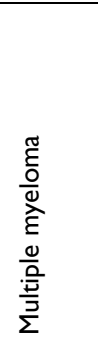 & 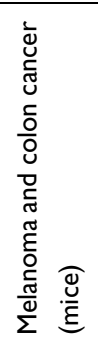 & 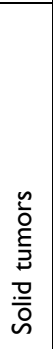 & 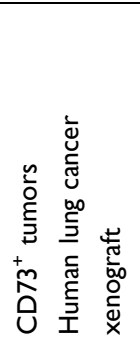 & 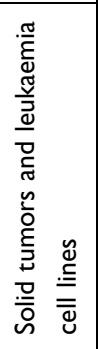 & 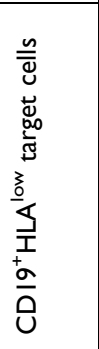 & 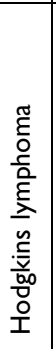 & 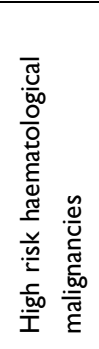 & 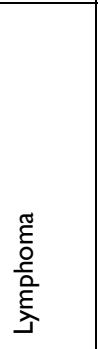 & 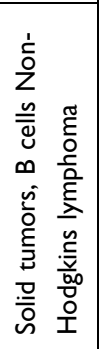 & 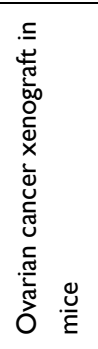 & । & 1 & 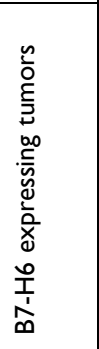 & 1 & 1 \\
\hline 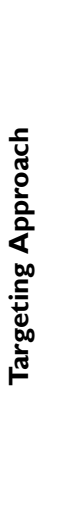 & 訔 & 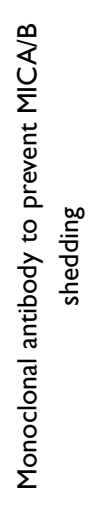 & 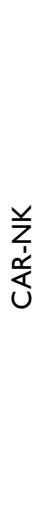 & & & 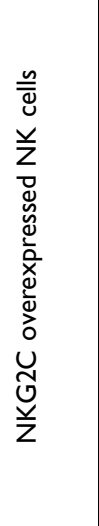 & 訔 & 店 & 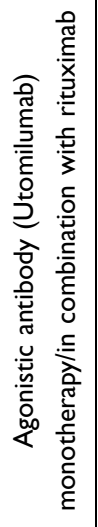 & 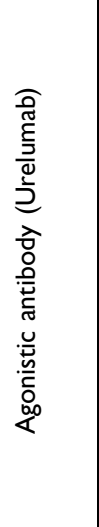 & 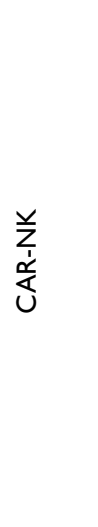 & । & 1 & 它 & 1 & I \\
\hline 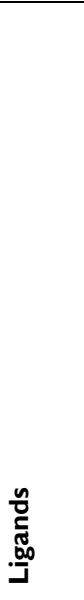 & 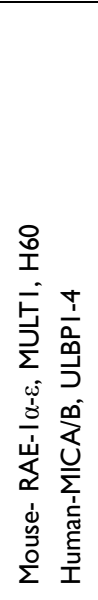 & & & & & 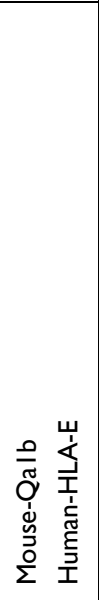 & 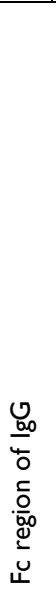 & & $\frac{\overrightarrow{0}}{\frac{\dot{m}}{\dot{t}}}$ & & 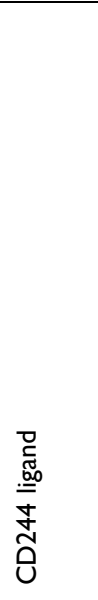 & 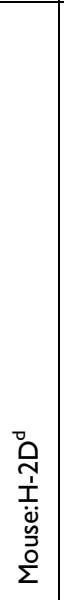 & 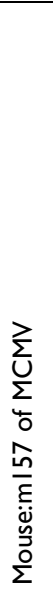 & 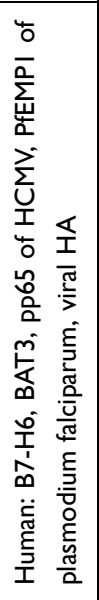 & 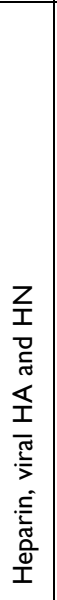 & 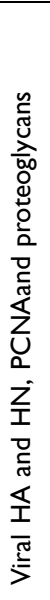 \\
\hline 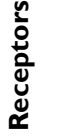 & 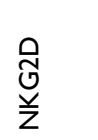 & & & & & 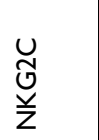 & $\frac{\circ}{0}$ & & $\frac{\varrho}{\frac{\varrho}{d}}$ & & 菾 & 足 & \begin{tabular}{l}
$\frac{1}{\sigma}$ \\
\multirow{2}{*}{}
\end{tabular} & $\begin{array}{l}\stackrel{0}{n} \\
\hat{n} \\
\frac{\tilde{z}}{z}\end{array}$ & $\begin{array}{l}\text { 古 } \\
\frac{2}{2} \\
\text { ż }\end{array}$ & $\begin{array}{l}\frac{y}{0} \\
\frac{z}{z}\end{array}$ \\
\hline
\end{tabular}




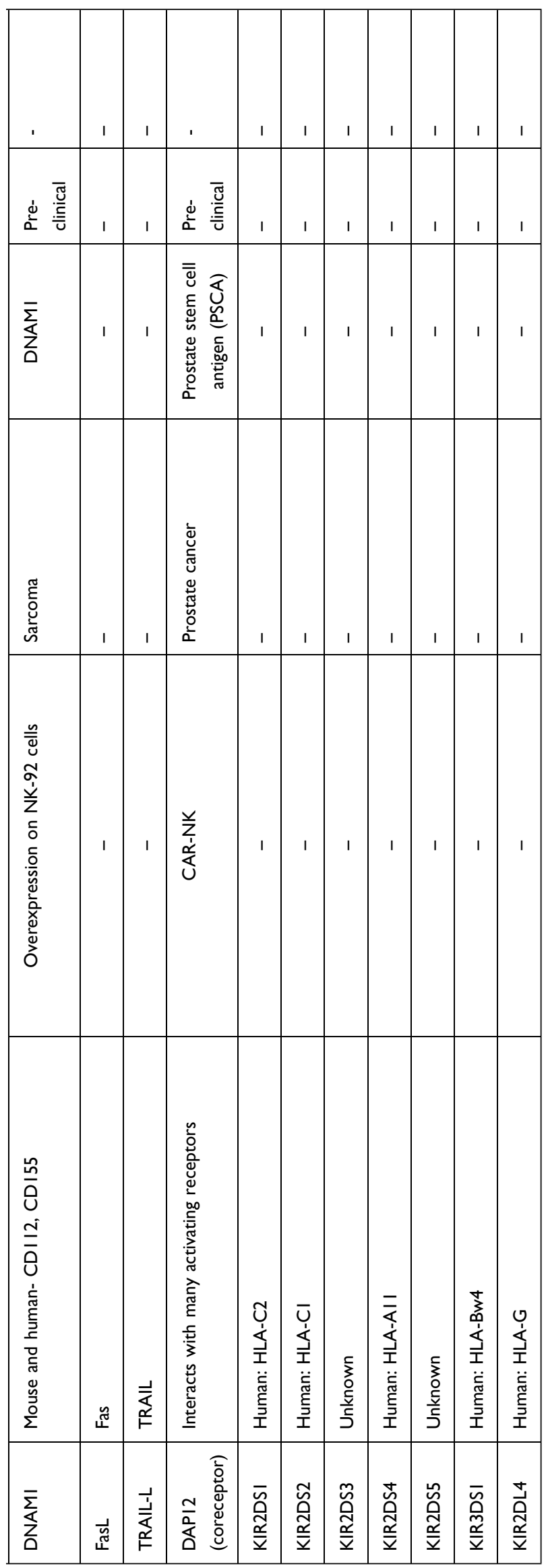




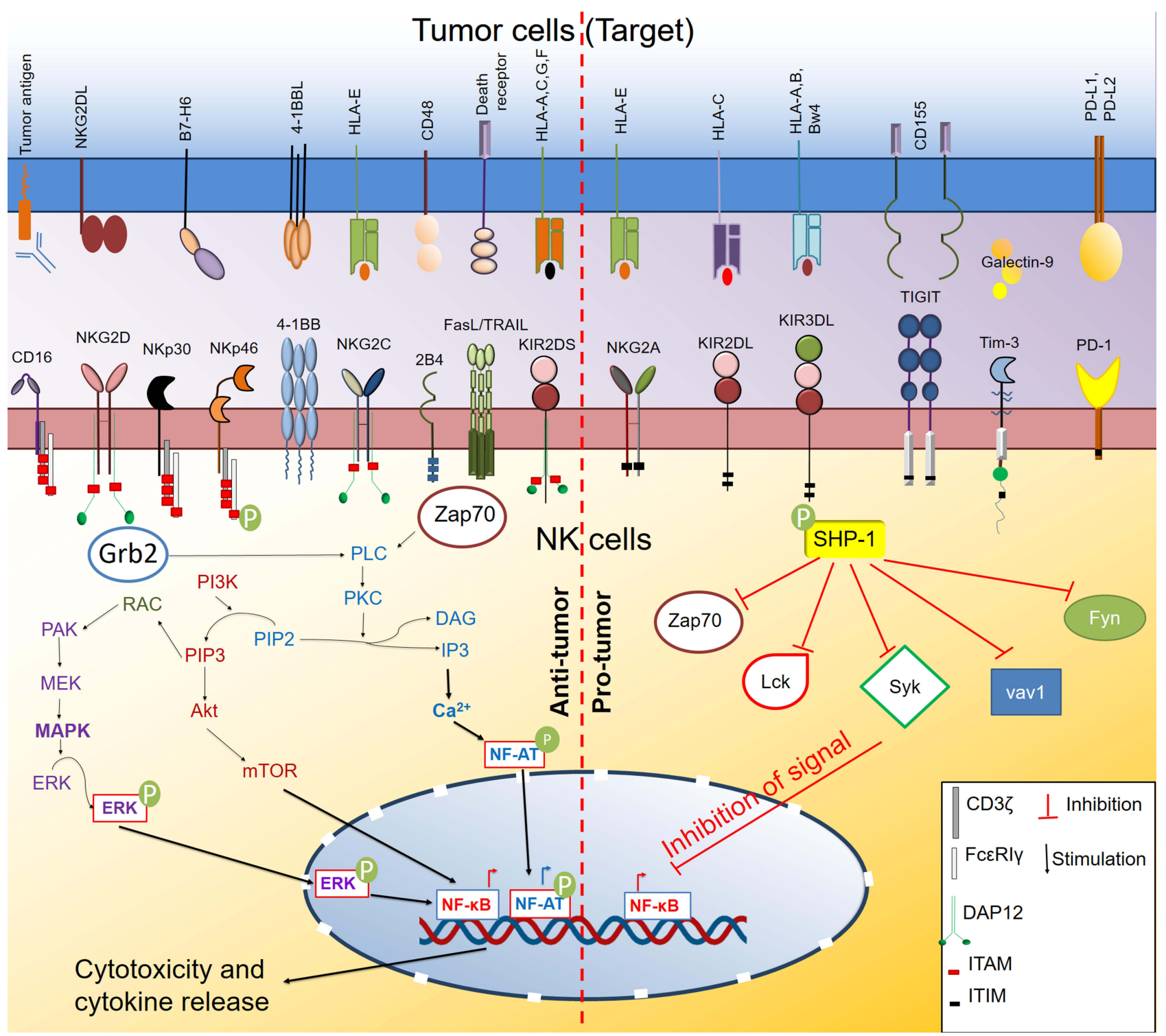

Figure I Activating and inhibitory receptors on NK cells and their signaling pathway. NK cells express various activating and inhibitory receptors. Upon interaction with their cognate ligands on the target (tumor) cell surface, they initiate a downstream signaling pathway that ultimately dictates the effector and cytotoxicity function of NK cells. The interaction of the activating receptor with their ligand initiates primarily mitogen-activated protein kinase (MAPK) and phosphoinositide-3 kinase (PI3K)/protein kinase $B(A k t) / M a m m a l i a n$ target of rapamycin (mTOR) pathway that activates nuclear factor- $\kappa B(N F \kappa)$ transcription factor. Activating receptors also activate the $\mathrm{Ca}^{2+}$ signaling pathway through phospholipase $\mathrm{C} \gamma(\mathrm{PLC} \gamma)$-protein kinase $\mathrm{C}$ (PKC) axis that further activates the nuclear factor of activated T cells (NF-AT) transcription factor. Activated NF- $\mathrm{KB}$ and NF-AT drive the production of cytokines and regulate the cytotoxic functions of NK cells. In contrast, the interaction of inhibitory receptors with their ligand activates the Src homology region 2 domain-containing phosphatase-I (SHP-I) that inhibits the functions of downstream signaling kinases and inhibits the activation of transcription factors like NF- $\mathrm{kB}$ and concurrently inhibits NK cell effector and cytotoxic function.

Abbreviations: 2B4, also known as Signaling lymphocyte activation molecule 4 (SLAM4) or CD244; 4-IBB, also known as Tumor necrosis factor ligand superfamily member 9 (TNFSF9) or CDI37; CDI6, also known as type III Fc receptor (FC $\gamma$ RIII); CD48, also known as B lymphocyte activation marker (BLAST-I) or signaling lymphocytic activation molecule 2 (SLAMF2); CDI55, also known as Poliovirus receptor (PVR); DAG, Diacylglycerol; DAPI0/I2, DNAX activating protein I0/I2; DNAM-I, DNAX accessory molecule- I; ERK, Extracellular signal regulated kinase; FasL, also known as TNFSF6, CD95L or CDI78; FceRly, Fc epsilon receptor I gamma; Grb2, growth factor receptor bound protein 2; HLA, Human leukocyte antigen; IP3, Inositol triphosphate; NKG2D/A/C, natural killer group 2D/2A/2C member; ITAM, Immunoreceptor tyrosine-based activation motif; ITIM, Immunoreceptor tyrosine-based inhibitory motif; KIRs, killer cell immunoglobulin-like receptors; Lck, Lymphocyte-specific protein tyrosine kinase; MAPK, Mitogen-activated protein kinase; MEK, MAPK kinase; NPp30, also known as Natural cytotoxicity receptor 3 (NCR3) or CD337; NKp46, also known as Natural cytotoxicity receptor I (NCRI) or CD335; PAK, P2I (PACI) activated kinase; PD-LI, programmed cell death ligand I (also known as CD274, B7HI); PDI, programmed cell death protein-I; PIP3, phosphatidylinositol (3, 4, 5)-triphosphate; TIM-3,T cell immunoglobulin and mucin-domain containing 3; RAC, Ras-related C3 bolulinum toxin substrate; Syk, Spleen tyrosine kinase; TIGIT, T cell Immunoglobulin and ITIM-domain; TRAIL, Tumour necrosis factor (TNF)-related apoptosis-inducing ligand; VavI, Vav guanine nucleotide exchange factor I; ZAP70, Zeta-chain-associated protein kinase 70. 
cell-mediated killing of the target cells. ${ }^{65,66}$ The activating or inhibitory receptor's function also depends on the association of downstream adapter molecule EAT-2, ERT, SAP, and other signaling pathway. ${ }^{28}$

Natural cytotoxicity receptors (NCRs) are immunoglobulin superfamily receptors that recognize many ligands, including bacterial, viral, parasite proteins, and several molecules from tumor cells. Mouse NK cells only express NKp46 while human NK cells express NKp46 (NCR1 or CD335), NKp44 (NCR2 or CD336), and NKp30 (NCR3 or CD337), and their expression is quite maturity and activation-dependent. Scientists have observed that NKp46 deficiency led to the impaired clearing of $\mathrm{T}$ cell lymphoma, melanoma, and lung metastasis. ${ }^{67}$ B7-H6, a ligand for $\mathrm{NKp} 30$, is essential for human NK cellmediated killing of K-562 cell. $^{68,69}$ People have tried to target the NKp30 pathway via different approaches to improve antitumor functions like CAR-NK therapy. ${ }^{70,71}$

CD38 is another activation molecule expressed on the NK cell surface that enhances the cytotoxicity of NK cells. CD38 is an enzyme that catalyzes the conversion of betanicotinamide adenine dinucleotide (beta-NAD ${ }^{+}$) and betanicotinamide adenine dinucleotide 2'-phosphate (beta$\mathrm{NADP}^{+}$) into cyclic adenosine diphosphate-ribose (ADPR) and nicotinic acid adenine dinucleotide phosphate (NAADP). ${ }^{72}$ Mallone et al showed that targeting CD38 with agonistic antibody enhanced the cytotoxic potential of NK cells by enhancing IFN- $\gamma$ and GM-CSF release. ${ }^{73}$

Costimulatory adhesion receptor DNAM1 is also responsible for tumor recognition by NK cells. It binds PVR and nectin-2, and its signaling leads to tumor recognition by NK cells and the migration of NK cell. ${ }^{74,75}$ The importance of DNAM1 in colorectal cancer, breast cancer, AML, and melanoma has been described. ${ }^{76-79}$ Not only cancer cells but cancer-associated fibroblasts can also inhibit NK cell function through DNAM1 signaling. ${ }^{80}$

CD16 (FC $\gamma$ RIIIA) is an immunoglobulin superfamily of receptors expressed on NK cells and other immune cells that recognize Fc regions of antibody opsonized on target cells. This mechanism is called antibody-mediated cellular cytotoxicity (ADCC). ${ }^{62}$ The NK cells then recognize and target to kill that antibody-coated target cell. ${ }^{81}$ About $40 \%$ of total NK cells in the body also express CD32 (FC $\gamma$ RIIC). The expression of isoforms of CD32 (FC $\gamma$ RIIC) on NK cells varies among humans. ${ }^{82}$ Among different isoforms, FC $\gamma$ RIIC-1 is more prominent among humans. Ernst et al showed that FC $\gamma$ RIIC-1 isoforms expressing $\mathrm{CD}^{+} 2^{+} \mathrm{NK}$ cells show a potent cytotoxic property than other isoforms expressing NK cells. ${ }^{83}$ Scientists also tried to target -ADCC mechanism by divalent or trivalent antibodies (BiKEs and TriKEs) to enhance the antitumor response of NK cells. Either alone or combined with other receptors and costimulatory molecules, these activating receptors activate NK cell functions. As this receptor signaling promotes NK cell cytotoxicity, they act as a potential target to promote the antitumor response of NK cells.

\section{Inhibitory Receptors on NK Cells and Their Role in Tumor Immunity}

NK cell-mediated cytotoxicity and release of proinflammatory cytokines can play an essential role in innate defense against viral infection and tumor cells. To restrain the over-activation of NK cells and protect normal healthy cells from NK cell-mediated cytolysis, scientists have promulgated the missing self-hypothesis. ${ }^{84,85}$ This hypothesis states that cells without self-MHC class I were susceptible to NK cell-mediated lysis. This observation played a significant role in discovering NK cell inhibitory receptors and describing their regulatory function.

The ITIM motif in the cytoplasmic tail of the inhibitory receptors governs the inhibitory signaling in NK cells. There are mainly two inhibitory signaling pathways. ${ }^{86}$ In this pathway, ITIM phosphorylation upon receptor-ligand interaction leads to recruitment of phosphatases such as Src homology-containing tyrosine phosphatase 1 (SHP-1), SHP-2, and lipid phosphatase SH2 domain-containing inositol-5-phosphatase (SHIP). SHP-1 and SHP-2 are involved in dephosphorylation of immunoreceptor tyrosine-based activation motif (ITAM)-containing Vav-1 and src family of tyrosine kinases such as Lck and Fyn (Figure 1). Early dephosphorylation of Vav-1 by SHP-1 inhibits actin-dependent NK cell activation signal blocking cytotoxicity. $^{28}$ Lck and Fyn belonging to the Src family of tyrosine kinase, are involved in the activation of the NK cells through the ITAM motif of activating receptor. Protein kinases ZAP70 and Syk act downstream of Lck tyrosine kinase. Engagement of NK cell inhibitory receptors inhibits tyrosine phosphorylation of Lck, ZAP70, and Syk via SHP-1 blocking NK cell activation. ${ }^{87,88}$ In the other pathways, Abl-1 kinase phosphorylates the Crk adaptor, dissociating from signaling complexes formed upon NK cell activation. The signaling through inhibitory receptors can be independent and also involve several other receptors and co-receptors. ${ }^{86}$ 


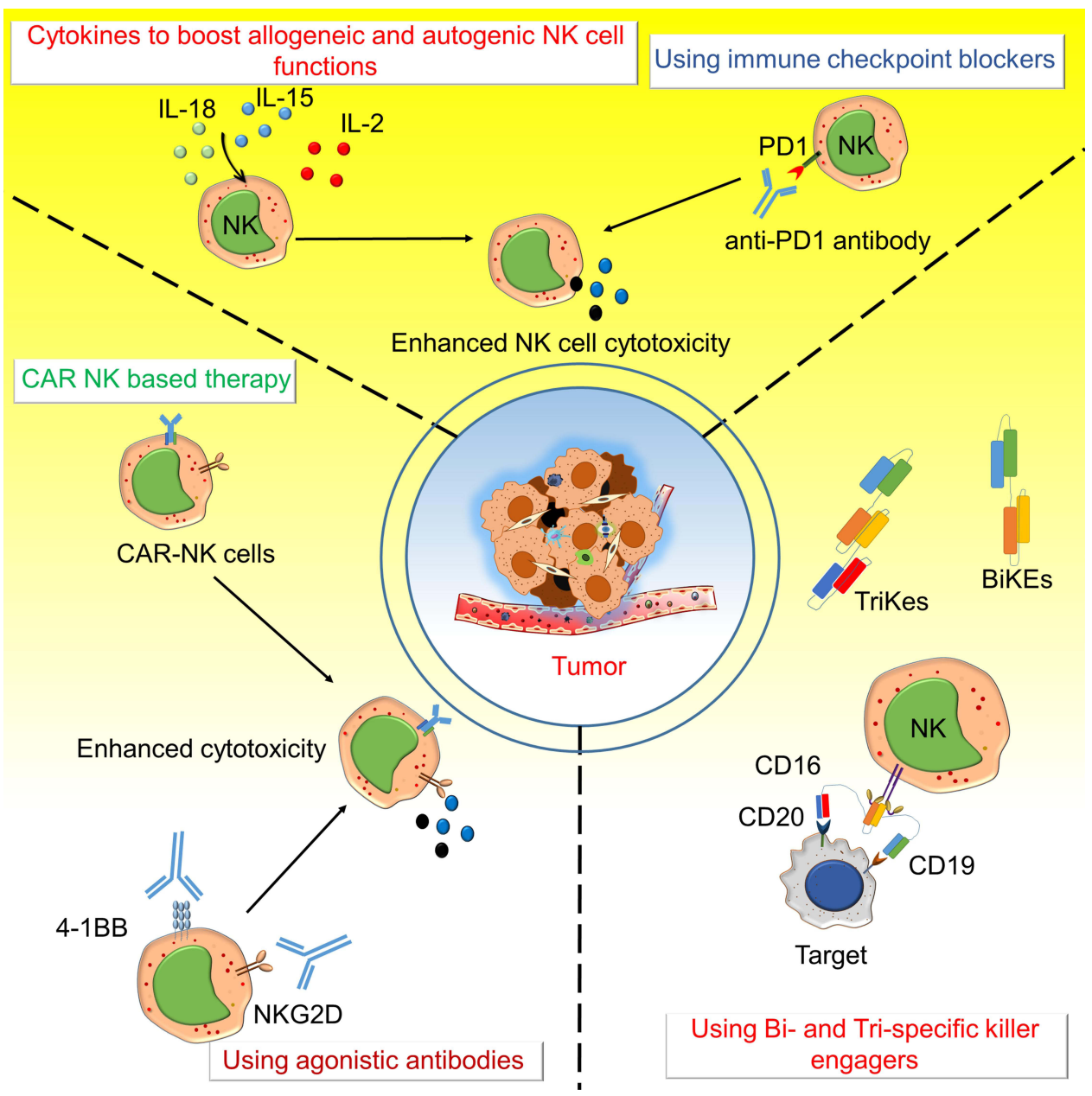

Figure 2 Various approaches to target NK cell activating and inhibitory receptors for anti-tumor immunity. The activating and inhibitory receptors on NK cells are targeted by several different strategies like Chimeric antigen receptors - natural killer (CAR-NK) cells, bi-specific killer engagers (BiKEs), and tri-specific killer engagers (TriKEs), agonistic antibody to NKG2D and 4-IBB, immune checkpoint blockers like an anti-PDI antibody, and using various cytokines to boost allogenic and autogenic or iPSC derived NK cells functions to boost anti-tumor immunity. CARs on NK cells were developed to target various molecules expressed on cancer cells to direct the NK cellmediated killing of cancer cells. BiKEs and TriKEs mainly engage some tumor antigens with Fc receptors (CDI6/CD32) of NK cells and enhance cytotoxic activity. Various agonistic antibodies target the activating receptors such as NKG2D and 4-IBB on NK cells and antagonistic antibodies of immune checkpoint molecules like anti-PDI to enhance anti-tumor activity. Different cytokines (IL-2 IL-I5 and IL-I8) are also used to increase the NK cell survival and activity.

Abbreviations: NKG2D, natural killer group 2D member; PD-I, programmed cell death protein I; iPSC, induced pluripotent stem cell; IL, interleukin.

Broadly, there are two types of inhibitory receptors regulating NK cell activation; HLA specific and nonHLA specific inhibitory receptors. The HLA-specific inhibitory receptors comprise KIR/CD158 family, CD94: NKG2A, LILRB1, and Ly49 inhibitory receptors. ${ }^{89}$ The murine Ly49 inhibitory receptors are structurally different from human KIR but perform a similar function, ie, recognizing class I MHC and delivering inhibitory signals to NK cells. Human KIR recognizes polymorphic class I specific HLA molecules, such as HLA-A, HLA-B, and HLA-C, whereas NKG2A recognizes non-classical HLAE molecule. ${ }^{90,91} \mathrm{NKG} 2 \mathrm{~A}$ is expressed during the early stages of NK cell development. KIR expression occurs later in mature NK cells. ${ }^{92}$ Several highly aggressive tumors (such as pancreas, lung, colon, liver, stomach, head, and neck) are found to overexpress the HLA-E ligand, which binds to NKG2A inhibitory receptor ${ }^{93,94}$ and inactivates NK cells. In the tumor microenvironment, secretion of anti-inflammatory cytokine TGF- $\beta$ along with $\mathrm{T}$ cell exhaustion upregulated NKG2A expression on $\mathrm{CD}^{+} \mathrm{T}$ cells. ${ }^{94-96}$ The expression profile of inhibitory receptors on NK cells varies across different subsets with differentiation. CD56 ${ }^{\text {bright }} \mathrm{NK}$ cells from peripheral human blood efficiently proliferate and secrete proinflammatory cytokines upon activation. However, these cells predominantly express the NKG2A receptor and are poorly cytotoxic. On the other hand, CD56 ${ }^{\mathrm{dim}} \mathrm{NK}$ cells are strongly cytotoxic and express NKG2A, KIR, or both. ${ }^{97}$ There is 
a progressive decline in the proliferation capacity with terminal differentiation and an increase in cytotoxicity of NK cells. In cytomegalovirus (CMV) infection, most mature NK cells in seropositive individuals comprise $\mathrm{CD} 57^{+} \mathrm{KIR}^{+} \mathrm{NKG} 2 \mathrm{~A}^{-} \mathrm{NK}$ cells. These cells also activate $\mathrm{NKG} 2 \mathrm{C}$ receptors and display adaptive immune characteristics such as recognizing HLA-E bound CMV peptides and show selective proliferation. ${ }^{98,99}$ This pathway leads to the generation of immune cell memory allowing for NK cell-mediated prevention of CMV re-infection in the future. LIRB1also called LIR1 inhibitory receptor, could recognize and interact with classical (HLA-A, HLA,-B and HLA-C) and non-classical MHC class I (HLA-G) molecules. ${ }^{89,100,101}$ LIRB1 also binds to UL18, a human CMV class I MHC homolog. ${ }^{102,103}$ High expression of LIR-1 and KIRs on NKG $2 \mathrm{~A}^{+} \mathrm{CD} 57^{+} \mathrm{NK}$ cells characterizes NK cell memory in CMV-positive patients. ${ }^{104}$

The non-HLA-specific inhibitory receptors on NK cells such as PD-1, SIGLEC-7, LAIR-1, and IRp60, along with HLA class I specific inhibitory receptors NKG2A, KIR, etc. play a significant role in regulating NK cell-mediated immune response. Several studies have shown the role of non-HLA-specific inhibitory receptors in regulating pyroptosis, inflammation, phagocytosis, immune cell proliferation, and response to viral infection. ${ }^{105-107}$

As the signaling through activating and inhibiting receptors governs NK cell cytotoxicity and modulates the killing of target cells, they are of interest to cancer immunologists. Some of the signaling from activating and inhibitory receptors are depicted in Figure 1. There are different ways to modulate receptors on $\mathrm{NK}$ cells and promote antitumor response, as shown in Figure 2. In the later section, we discussed several approaches used by scientists to manipulate the activating and inhibitory receptor functions to enhance antitumor functions of NK cells.

\section{Targeting the Stimulatory and Inhibitory Receptors of NK Cells Activating Receptors \\ Enhancement of Activation Receptor-Mediated Cytolytic Activity}

In ADCC, the engagement of the CD16 receptor on NK cells with opsonized target cells through the Fc region of an antibody mediates NK cell cytotoxicity. ${ }^{108}$ The CD16 receptor on NK cells can be activated using bispecific killer engagers (BiKEs) (Figure 2). BiKEs contain two single-chain variable antibody fragments that simultaneously bind a tumor antigen and CD16 receptor to NK cells and show promising results against solid tumors and leukemia. ${ }^{109}$ BiKEs are targeting epithelial cell adhesion molecules (EpCAMs), HER2, and EGFR for solid tumors or CD19, CD33, and CD20 for hematological malignancies. CD16 on NK cells showed a good response against both solid tumors and acute myeloid leukaemia. $^{109}$ NK cell activating receptor NKG2D is also targeted through BiKEs. A bispecific antibody CS1NKG2D containing anti-CS1scFv and an anti-NKG2D scFv showed potently and dose-dependent cytotoxicity against multiple myeloma both in vitro and in vivo. ${ }^{110}$ Scientists also developed another tetravalent BiKE AFM13 that contains tandem antibodies against CD16 and CD30. AFM13 has a higher affinity for the Fc receptor and has a longer half-life than other BiKEs and TriKEs. AFM13 also shows good tolerability and safety in relapsed/refractory Hodgkin's lymphoma patients, and $77 \%$ of patients had stable disease. ${ }^{29,111,112}$ It is currently in Phase II monotherapy clinical trial in relapsed/refractory Hodgkin's lymphoma. ${ }^{113}$ Tri-specific Killer engagers (TriKEs) (Figure 2) have also been developed, which link CD16 to CD19 and CD22. ${ }^{114,115}$ TriKEs were modified to deliver IL-15 in the vicinity of action and also improved the durability of $\mathrm{NK}$ cell response. ${ }^{116}$ Vallera et al showed that CD33/IL-15/CD16 TriKEs has a potent anti-cancer response and prolonged in vivo persistence due to IL-15. ${ }^{116}$ This TriKE strategy (GTB-3550) is currently in a clinical trial to treat high-risk hematological malignancies (NCT03214666). ${ }^{116}$ 1615EpCAM TriKE (EpCAM/IL-15/CD16), also developed that targets EpCAM on many cancers of epithelial origin, significantly showed enhanced NK cell proliferation, cytolytic properties, and cytokine secretion in vitro. ${ }^{117}$ Gauthier et al also reported using engagers in improved NK cell response when linking tumor antigens with both CD16 and NKp46 in NK cells. ${ }^{118}$

Chester et al reported that anti-4-1BB agonistic antibodies have potent antitumor responses in mice. ${ }^{119}$ However, treatment with anti-4-1BB monoclonal antibody urelumab in patients with advanced-stage solid tumors increases the level of interferon-induced cytokines and transaminitis at a higher dose. ${ }^{120}$ However, another anti4-1BB monoclonal antibody, utomilumab, is well tolerated in 55 patients. With this treatment, two out of 15 patients with advanced Merkel cell carcinoma showed a durable response. $^{121}$ Researchers also tried to target NKG2D function to stimulate $\mathrm{NK}$ cell activity. In tumors expressing 
a high level of NKG2D ligand, MICA/B can downregulate NKG2D expression on $\mathrm{NK}$ cells and $\mathrm{CD} 8^{+}$ T cells. Antibody targeting MICA/B, IPH4301 potentiates the cytotoxic properties of NK cells in vitro and in vivo and prevents NKG2D down regulation. ${ }^{12}$ Ferrari et al showed that antibody targeting $\alpha 3$ segment of MICA that prevent soluble MICA/B shedding enhance the antitumor activity in multiple murine and human tumor models, mainly by stimulating NK cell activity through NKG2D and CD16. ${ }^{122}$

\section{Use of Allogeneic NK Cells for Cell for Immunotherapy}

NK cells from allogeneic donors are advantageous in cell-based therapy as they do not result in graft versus host disease (GVHD) as with allogeneic $\mathrm{T}$ cells. Alloreactive NK cells are delivered to the host either by adoptive cell transfer or thorough hematopoietic stem cell transfer (HSCT). Allogenic NK cells are prepared mainly from cell lines, adult donor lymphapheresis products, or umbilical cord blood cells. There are few benefits in using allogeneic NK cells over autologous cells. As these cells are educated in healthy donors than in tumor-bearing individual, they are more cytotoxic and possesses better antitumor activity. ${ }^{123}$ Another study by Ruggeri et al showed that KIR ligand mismatches between donors and patients are associated with better outcomes in myeloid leukemia after T-cell-depleted haploidentical hematopoietic cell transplantation. ${ }^{124}$ Allogeneic NK cells could be expanded in vitro using various doses of cytokines such as IL-2, IL-15, and IFN- $\gamma$ before administering to the patients. ${ }^{125}$ Immunosuppression is a perquisite for NK cell adoptive transfer or in HSCT. Combining NK cells adoptive transfer with a chemotherapeutic regimen with high doses of cyclophosphamide (Cy) and fludarabine (Flu) led to better in vivo expansion of NK cells. ${ }^{126}$ This Hi$\mathrm{Cy} /$ Flu regimen led to pancytopenia and induction of IL15 secretion in vivo, which resulted in the expansion of allogeneic NK cells. ${ }^{127,128}$ Geller et al also used this Hi$\mathrm{Cy} / \mathrm{Flu}$ regimen in NK cell-based therapy in metastatic recurrent breast cancer settings that already underwent phase II clinical trial. ${ }^{129}$

\section{CAR-Modified NK Cells in Cancer Immunotherapy}

The recent development of CAR T cells widened the horizon of cancer immunotherapy. CAR-T cells targeting CD19 in B cell acute lymphoblastic leukemia (B-ALL) showed promising outcomes in other relapsed non-Hodgkins lymphoma with $70-90 \%$ success rates. FDA has also approved this CAR-T cell therapy to treat ALL and diffuse large B cell lymphoma. Currently, scientists have developed various CAR-T cell approach to treat several hematological malignancies and solid tumor. ${ }^{79}$ However, there are certain drawbacks to this therapy. The CAR-T sometimes develops GVHD, cytokine release syndrome, and neurotoxicity. From this perspective, CAR-NKs are much safer and more potent as their response is not MHC restricted and produces fewer side effects. Apart from CARs, CAR-NK cells also retain several ligands and receptors for stress signals, including CD226, NKp30, NKp46, NKG2D, and NKp44. NK cells express FcrRIII (CD16) and stimulate an antitumor response in a CAR-independent and CARdependent manner. ${ }^{130,131}$ The CAR-NK cells developed from the NK-92 cell line or through autologous or allogenic hosts show some unresponsiveness towards target cell killing. The activating signal incorporated in the CARs made these cells overcome this shortcoming and the potent inhibition posed by the NKG2A signaling. ${ }^{132}$ Oei et al also showed that adaptive NK cells that express NKG2C, CD57, and self HLA specific KIRs possess a superior ability to kill $\mathrm{CD} 9^{+} \mathrm{HLA}^{\text {low }}$ target cells. ${ }^{132}$ Zhuang et al reported that incorporating $\mathrm{CD} 28$ homolog protein $(\mathrm{CD} 28 \mathrm{H})$ in CARs triggers substantial lysis of $\mathrm{B} 7 \mathrm{H}^{+} \mathrm{HLA}^{+} \mathrm{E}^{+}$tumor cells and makes them overcome the potent inhibition triggered by the NKG2A signaling. ${ }^{133}$

To date, people have tried to develop different approaches to produce CAR-NK cells. However, the primary targets in hematological malignancies include CD33, CD22, and CD19 for relapsed and refractory leukemia and for lymphoma CD7 are used in several clinical trials (NCT03824951, NCT02742727, NCT02944162, NCT03692767, NCT03056339, NCT03579927, NCT02892695, NCT03690310, and NCT01974479). ${ }^{134}$ In multiple myelomas, the B cell maturation antigen is used as a target (NCT03940833). In hematological malignancies, a few targets are also explored in several solid cancers currently under clinical trial. These targets are mucin1, NKG2D ligands, roundabout guidance receptor (ROBO1), mesothelin, and human epidermal growth factor receptor 1 (NCT03692637, NCT03383978, NCT03940820, NCT03692663, NCT03931720, NCT03415100, NCT03941457, NCT02839954). ${ }^{79}$

Scientists also used the piggyBac transposon system ${ }^{135}$ to incorporate NKG2D in the CAR in NK-92 cells. These 
non-viral engineered CAR-NK cells showed potent antitumor immunity against the xenograft model of human lung cancer in mice alone or combined with CD73 blockade. ${ }^{136}$ First, NK cell-based CAR was designed to have NKG2D-DNAX activation protein 10 (DAP10)CD3 $\zeta$ construct. This CAR-NK cell showed potent cytotoxic properties in both in vitro as well as in the mouse model of osteosarcoma. ${ }^{137}$ This NKG2D-CAR-NK can recognize about $90 \%$ of human cancers that express ligands of NKG2D. Not only cancer cells, several immunosuppressor cells in the tumor microenvironment like MDSCs and Tregs also express ligands for NKG2D. These NKG2D-CAR NK cells can also eliminate these cells and promote antitumor activity. ${ }^{138}$ Apart from NKG2D, other activating receptors of NK cells such as NKp30 and DNAM-1 were used for making CARs to broaden the horizon of CAR-NK cell-mediated killing. For example, (PSCA)-DAP12 CAR is designed to target prostate stem cell antigen developed from primary NK cells and the YTS-NK cell line. These CAR-NK cells performed better cytotoxicity compared to PSCA-CD3 $\zeta$ based CAR NK cells, even in the absence of other costimulatory ligands. ${ }^{70,71}$ The optimal signaling through CARs in NK cell cytotoxicity $\mathrm{CD} 3 \zeta$ signaling domain, the intracellular 2B4 domain, and the transmembrane NKG2D are necessary. This knowledge was used to develop mesothelin-specific CAR-NK cells. These CARs showed potent antitumor action against murine ovarian cancer xenograft model. ${ }^{71}$

The inclusion of the IL-15 sequence in the CAR-NK sequence enhanced the efficacy and persistence of CARNK cells. ${ }^{139}$ Depending upon the type of cancer and the antigen expressed, several tumor-specific targets of NK cells are used for CAR generation in the preclinical set up to increase the efficacy of CAR-NK cells. These targets include NKG2D ligand, glucosylceramide beta, epidermal growth factor receptor (EGFR), HER-2, EGFRvIII, epithelial cell adhesion molecules, glypican 3, guanine nucleotide-binding protein alpha-7, CD19, CD20, CD138, CD5, and CD2 subset $1(\mathrm{CS} 1){ }^{140-142}$

Though CAR-NK shows more significant potential to target and eliminates tumors, there are many challenges with CAR-NK cell therapy. First of all, NK cells are hard to transduce, so genetic modification is hard to perform. Even after their generation, allogeneic NK cells have a brief life span both in vivo and in vitro, limiting their durability of antitumor response. ${ }^{143}$ The scientists' also used iPSCderived NK cells to develop CAR-NK cells, and they hold much promise in the future of "off-the-shelf" CAR-NK therapy. For example, mesothelin targeting CAR-NK cells developed from human iPSCs showed promising cytotoxicity potential against ovarian cancer. ${ }^{71,144-147}$ Though there are challenges, this CAR-NK cell strategy holds great potential either alone or combined with other therapies (checkpoint blockade) in the future. ${ }^{148}$

\section{By "Priming" NK Cells to Perform Cytotoxicity}

Although adoptive transfers of autologous and allogeneic or CAR-NK cells showed a favorable response, the major challenge of these therapies is the durability and apoptosis of these cells in the patients. Researchers also used different cytokines cocktails to "prime" the NK cell response in vivo. These primed NK cells show a more durable response in patients than NK cell. ${ }^{149}$ Before injection, sometimes these NK cells are stimulated with either IL-2 or IL-15, or sometimes used along with NK cell infusions. ALT-803, a fusion protein of IL-15/IL-15a, has augmented NK cell activity and ADCC-mediated cytotoxicity both in vitro and in vivo. Recently, different groups showed NK cells primed with IL-12/IL-15, and IL-18 showed a potent and sustained antitumor response and showed the development of memory-like phenotype. $^{150-152}$

Apart from cytokine-mediated priming, there are also other strategies used to prime NK cells for better cytotoxicity. Cichocki et al used GSK3 inhibitors to enhance NK cell activity. They showed that IL-15 primed human peripheral blood NK cells in the presence of GSK3 inhibitor ex vivo; they showed better cytotoxicity and antitumor activity. This strategy is used to develop FATE-NK100, which is currently undergoing Phase I clinical trial either alone or in combination with other monoclonal antibodies to treat the advanced stage of solid tumors (NCT03319459). ${ }^{153}$ In another strategy, North et al reported overnight coincubation of leukemia cell line CTV-1 or its lysate with NK cells without cytokines enhanced its cytotoxicity against non-responsive cancer cells in vitro. ${ }^{154}$ Based on these preclinical results, CTV-1 lysate primed human NK cells (CNDO-109-NK cells) were evaluated for phase I clinical trial (NCT01520558) against high-risk AML patients after first complete remission. ${ }^{155}$

\section{Inhibitory Receptors}

Targeting Inhibitory Receptors on NK Cells to Promote Antitumor Response

During cancer progression, tumor cells sometimes downregulate or lose their expression of $\mathrm{MHC}$ class 
I molecule. ${ }^{156}$ At the same time, transformed cells upregulate the ligands specific to NK cell activation receptors. This transformation results in increased NK cell-mediated cytolysis of transformed cells and a reduced tumor burden. $^{89}$

\section{HLA-Specific NK Cell Inhibitory Receptor-Ligand Interaction and Therapeutic Application}

Cancer cells have evolved different strategies to evade killing by NK cells and facilitate immune escape. These include over-expression of HLA class I (such as HLA-E, HLA-G) on cancer cells specific to inhibitory NK cell receptors and inducing inhibitory checkpoints (such as PD-1, TIM-3, Tactile, IRp60, etc.) on NK cells.

\section{NKG2A}

In addition to the NK cells, NK T cells, $\gamma \delta \mathrm{T}$ cells, $\mathrm{CD} 8^{+}$ $\mathrm{T}$ cells, and subsets of innate lymphocytes also express CD94/NKG2A. Scientists also reported that head and neck squamous cell carcinoma (HNSCC) patients' NK cells show $\sim 50 \%$ co-expression of CD94/NKG2A. ${ }^{157}$ Blocking NKG2A with monoclonal antibody $(\mathrm{mAb})$ monalizumab restores cytotoxicity of both NK cells and $\mathrm{CD} 8^{+} \mathrm{T}$ cells, enhancing antitumor immunity. ${ }^{157,158}$ Preliminary clinical studies of aggressive human tumors have shown favorable outcomes upon treatment with a monoclonal antibody $(\mathrm{mAb})$ specific to NKG2A used alone or combined with $\mathrm{mAb}$ specific to a tumor antigen or checkpoint inhibitors. Therapeutic mAbs specific for PD-1/PD-L1 (durvalumab), when used in combination NKG2A blocking mAbs, enhances the secretion of proinflammatory cytokine IFN- $\gamma$ and cytotoxicity of HLA-E $\mathrm{E}^{+}$ K562 cancer cells by NK and T cells. ${ }^{94}$

In patients with squamous cell carcinoma of the head and neck (SCCHN), the use of anti-NKG2A monalizumab along with anti-EGFR mAb cetuximab show improved clinical outcomes in phase II trials. Combination of monalizumab with cetuximab potentiated antibody-dependent cell cytotoxicity of SCCHN cell line. ${ }^{94}$ Together, these studies suggest that blocking inhibitory receptors increases the NK cell cytotoxicity and ADCC of tumor cells in the presence of tumor antigen-specific antibodies.

\section{Lymphocyte Activating Gene 3 (LAG3)}

LAG3 is known to bind to MHC II and interacts with galactin 3, $\alpha$-synuclein fibrils ( $\alpha$-syn), and FGL-1 molecule. ${ }^{159}$ Expression of LAG3 is reported on CD4 $\mathrm{T}$ cells, regulatory CD4 $\mathrm{T}$ cells, $\gamma \delta \mathrm{T}$ cells, NK cells,
invariant-NKT cells, B cells, and plasmacytoid dendritic cells. ${ }^{159}$ One among the three splice variants of LAG3 exists in soluble form. ${ }^{159}$ LAG-3 inhibitory receptor is associated with exhaustion of tumor-infiltrating $\mathrm{T}$ cells and immune suppression. The synergy between LAG3 and PD-1 inhibitory pathway facilitates the immune escape of tumor cells by regulating T cell function. ${ }^{160,161}$ The effect of LAG3 expressed on NK cells on tumor progression is yet to be elucidated.

\section{HLA-G}

HLA-G, expressed by trophoblast cells, is involved in the tolerance of the fetus during pregnancy ${ }^{50,101}$ HLA-G interacts with KIR2DL4 and ILT2 expressed in NK cells. Several tumors highly express HLA-G, which limits antitumor response by impairing NK cell and T cell-mediated cytotoxicity. HLA-G on tumors can also induce Treg formation and accumulation of MDSC. ${ }^{162}$ Francois Anna et al have reported generating therapeutic CAR $\mathrm{T}$ cells specific to immunosuppressive HLA-G isoforms expressed on cancer cells. ${ }^{163}$ CAR-NK and T cells specific for HLA-G might represent a novel strategy in the treatment of cancer.

\section{Killer Cell Immunoglobulin-Like Receptor (KIR)}

KIR molecules recognize the motif of MHC I molecules and show an inhibitory response. KIR plays a significant role in leukemia treatment. $\mathrm{KIR}^{+}$alloreactive NK cells effectively treat acute myeloid leukemia upon hematopoietic stem cell transfer. The transfer of NK cells from haploidentical donors leads to KIR-KIR-L mismatch in the host resulting in alloreactive $\mathrm{KIR}^{+} \mathrm{NK}$ cells efficiently clearing leukaemia. ${ }^{164-168}$ Immunotherapy targeting KIR by improving antitumor immune response is also currently in focus. IPH4102, an anti-KIR3DL2 monoclonal antibody, showed encouraging clinical outcomes in patients with cutaneous T cell lymphoma in Phase 1 trials. ${ }^{169}$ The genotype of KIR and its associated HLA ligands play an important role in influencing tumor progression and efficacy of immunotherapy in some cancers across different individuals. In high-risk neuroblastoma, patients without one or more HLA ligands for NK cell inhibitory KIRs had a higher survival rate than patients with all inhibitory KIR ligands following autologous hematopoietic stem cell transplantation. ${ }^{170}$ Anti-disialoganglioside (GD2) effectiveness in mAb therapy was significantly improved in patients with NK cells lacking self HLA Class I ligand for inhibitory KIRs. ${ }^{171}$ Patients having inhibitory KIR2DL2 with its ligand HLA C1 and KIR3DL1 with 
its ligand HLA-Bw4 showed improved outcomes to immunotherapy in both neuroblastoma and follicular lymphoma. ${ }^{172,173}$ Therefore determining patient KIR genotype might help design a better anti-tumoral regimen to improve survival in high-risk cancer.

\section{Non-HLA Specific Inhibitory NK Cell Receptors and Therapeutic Applications}

Tumor cells induce the expression of non-HLA-specific inhibitory receptors along with HLA-specific inhibitory receptors on NK cells to evade immunosurveillance and cytolysis.

\section{Programmed Cell Death Protein I (PD-I)}

PD-1 (also known as CD279), belonging to the CD28/ CTLA4 subfamily of inhibitory checkpoint regulators, are expressed on T cells, B cells, myeloid cells, and NK cells. ${ }^{174}$ High expression of PD-1 in NK cells was reported in gastric cancer, multiple myeloma, Kaposi sarcoma, malignant mesothelioma, and adenocarcinoma, ${ }^{107}$ which also correlates with poor survival in oesophageal and liver cancer. ${ }^{175}$ PD-1 expression on NK cells leads to functional impairment and NK cell exhaustion and promoting tumor escape. Blocking PD-1 augmented proinflammatory cytokine production, decreased apoptosis of NK cells, and increased cytotoxicity of $\mathrm{PD}-\mathrm{L}^{+}$tumor cells without affecting surrounding healthy cells. ${ }^{175-177}$ Analysis of factors in the tumor microenvironment (TME) promotes upregulation of PD-1 on NK cells revealed the vital role of glucocorticoids and cytokines IL-12, IL-15, and IL-18 in increasing PD-1 expression on NK cells. ${ }^{178}$ Immunotherapy involving monoclonal antibodies blocking PD-1/PD-L1 is currently an effective therapeutic regimen for cancer treatment. ${ }^{179,180}$ Inhibition of PD-1 leads to activation of both cytotoxic $\mathrm{CD}^{+} \mathrm{T}$ cell and NK cells, generating a potent antitumor immune response. However, response to PD-1 immunotherapy varies from patient to patient and across different cancers because of tumor heterogeneity, genetic polymorphism, and response to different antibody clones. ${ }^{181,182}$

\section{T Cell Immunoglobulin- and Mucin-Domain- Containing Molecule-3 (TIM-3)}

TIM3, also known as Hepatitis A virus cellular receptor 2 (HAVCR2), is expressed on Th1, Th17, Treg, DCs, and mature NK cells. Increased TIM3 expression was observed in tumor-infiltrating leukocytes in melanoma, lung cancer, lymphoma, gastric, head, and neck cancer. TIM3 expression in NK cells correlated with poor prognosis and shorter survival in patients with metastatic melanoma and lung adenocarcinoma. ${ }^{183}$ Blockade of TIM3 reverses the NK cell exhaustion and enhances the cytolysis and secretion of proinflammatory cytokines by NK cells. $^{184,185}$ TIM-3 is also suggested as a potential prognostic biomarker for patients with solid tumors. ${ }^{186}$

\section{T Cell Immunoreceptor with Immunoglobulin and ITIM Domain (TIGIT)}

TIGIT (also known as WUCAM, Vstm3, VSIG9), an inhibitory receptor expressed in $\mathrm{T}$ cells and NK cells, interacts with two ligands, CD155 (PVR) and CD112 (PVRL2, nectin-2) expressed on DCs, macrophages, etc., resulting in immune tolerance. ${ }^{187}$ TIGIT contributes to immune suppression by inhibiting both T cell and NK cellmediated immune responses. High TIGIT expression is associated with poor prognosis and tumor progression in different cancer. ${ }^{187}$ TIGIT deficiency in vivo led to reduced tumor growth and increased secretion of proinflammatory cytokine IFN- $\gamma$ by $\mathrm{CD}^{+} \mathrm{T}$ cells and NK cells in a colorectal cancer model. ${ }^{188}$ Antibody-mediated inhibition of TIGIT/PVR interaction restored $\mathrm{CD}^{+} \mathrm{T}$ cell activation and decreased tumor burden. Blockade of TIGIT impedes NK cell exhaustion, augments NK cell memory response to tumor re-challenge, and promotes NK cell-dependent adaptive immunity to tumor cells in a mouse model of melanoma and colon cancer. ${ }^{188,189}$ Inhibition of TIGIT enhances the antitumor efficacy of PD-1/PD-L1 immunotherapy. Indeed, combinatorial therapy involving blockade of both TIGIT and PD-1 leads to improve survival and generation of a potent antitumor immune response to glioblastoma. ${ }^{190}$

\section{Sialic Acid-Binding Ig-Like Lectin 7 (Siglec 7)}

Siglec 7 is a member of the sialic acid-binding immunoglobulin-like lectins (Siglecs) family, expressed mainly on NK cells and monocytes. Siglec- $7^{+}$NK cells show increased expression of activating receptors CD38, CD16, DNAM1, NKp30, NKp46, and low expression of NKG2A and CD158a molecules. ${ }^{191}$ Overexpression of sialyltransferase in tumor cells and dysregulation of sialidase leads to increase expression of sialylated glycan on the surface of tumor cells. Engagement of Siglec 7 and other Siglec receptors, such as Siglec 9 with sialylated glycans in malignant cells of different types of cancer, was found to attenuate NK cell-mediated antitumor immune response. ${ }^{192}$ Powerful therapeutic strategies 
targeting immune suppression through inhibitory receptors include desialylation of cancer cells and inhibiting hypersialylation of cancer cells. A complex of sialidase with human epidermal growth factor receptor 2 (HER2) targeting therapeutic $\mathrm{mAb}$ trastuzumab abrogated ligands for inhibitory Siglec receptors (Siglec 7 and Siglec 9), potentiating NK cell-mediated ADCC. ${ }^{193}$ Sialic acid blockade by sialyltransferase inhibitor 3Fax-Peracetyl Neu5Ac reduces melanoma tumor growth, suppresses lung metastases, and increases intratumoral infiltration of NK cells and effector CD8 ${ }^{+}$T cells. ${ }^{194,195}$ CAR-T cells have great potential in the treatment of hematological malignancies. Siglec-7/9-based CAR-T cells display potent cytotoxicity against hypersialylated targets and reduced tumor growth. ${ }^{196}$

\section{Interleukin-I Receptor 8 (IL-IR8)}

IL-1R8, also known as single immunoglobulin IL-1Rrelated receptor (SIGIRR, or TIR8), is a member of the IL-1R family. IL1R8 negatively regulates ILR and TLR downstream signaling pathways, preventing pathology due to excessive inflammation upon pathogenic infection. ${ }^{197}$ IL-1R8 is known to act as a checkpoint for NK cell maturation and effector function and regulates the antitumor and anti-viral activity of NK cells. ${ }^{198}$ Enhanced maturation and upregulation of activation receptors Ly49H, NKG2D, and DNAM-1 were observed on NK cells deficient for IL-1R8. The absence of inhibitory IL$1 \mathrm{R} 8$ receptor on NK cells was found to be associated with inhibition of liver carcinogenesis and metastasis. ${ }^{198}$

\section{Leukocyte-Associated Immunoglobulin-Like} Receptor-I (LAIR-I)

LAIR-1, also known as CD305, is a widely expressing inhibitory receptor. Differentiation and activation of immune cells are associated with the downregulation of LAIR-1 expression. ${ }^{199-201}$ The high expression of LAIR-1 in hematopoietic cancers, AML, and CLL correlate with poor prognosis. ${ }^{202}$ The interaction between the inhibitory LAIR1 receptor and its ligand, extracellular matrix collagen, was associated with resistance to anti- PD-1 immunotherapy and $\mathrm{CD} 8^{+} \mathrm{T}$ cell exhaustion in melanoma. ${ }^{203}$ Cross-linking of LAIR-1 with monoclonal antibody leads to inhibition of NK cell cytotoxicity. ${ }^{204}$ Thus blocking LAIR-1 can be a potential therapeutic strategy to enhance NK cell activation and kill cancer cells. High expression of LAIR-1 is reported to be clinically associated with poor outcomes in breast carcinoma. ${ }^{205}$
Killer Cell Lectin-Like Receptor Subfamily G Member

\section{I (KLRGI)}

KLRG1, an inhibitory C-type lectin receptor, is expressed in humans and mice by memory T cells and NK cells. The biological ligand of the KLRG1 receptor is E-cadherin and $\mathrm{N}$-cadherin with similar affinities $(7-12 \mu \mathrm{M}){ }^{206,207}$ Blocking of KLRG1 receptor leads to decreased tumor growth and metastasis in melanoma, breast cancer, and colon cancer. ${ }^{208,209}$ KLRG1 inhibition increases the maturation and accumulation of NK cells along with effector $\mathrm{CD}^{+} \mathrm{T}$ cells in the tumor microenvironment. The antitumor efficacy of PD-1 therapy enhances by synergistic blockade of KLRG1in melanoma and breast cancer, ${ }^{209,210}$ suggesting its role as an essential checkpoint inhibitor in cancer immunotherapy.

\section{CD300a}

CD300a (also known as IRp60) inhibitory receptor, a member of the CD300 family, is expressed in several lymphoid and myeloid cells. CD300a is involved in the regulation of several physiological processes, including phagocytosis and inflammation. ${ }^{107} \mathrm{CD} 300 \mathrm{a}$ can inhibit NK cell-mediated cytolysis. ${ }^{211}$ CD300a recognize and interact with phosphatidylserine (PS) and phosphatidylethanolamine expressed on the surface of infected, apoptotic, and tumor cells. ${ }^{212-214}$ The interaction of PS on tumor cells with CD300a on NK cells prevents NK cell-mediated cytotoxicity of tumor cells. ${ }^{213}$ High expression of $\mathrm{CD} 300$ a correlates with poor prognosis in AML and diffuse large $B$ cell lymphoma (DLBCL). ${ }^{215,216}$ Suppression of CD300a expression leads to reduced tumor growth in an in vivo DLBCL xenograft model. ${ }^{216}$

\section{Conclusion and Future Perspective}

The cytotoxic capacity of NK cells ultimately depends on activating and inhibiting receptors on them with their cognate ligands on the target cells. Understanding the biology of NK cell activating and inhibitory receptors paves the way to modulate them for better antitumor functions. Both antibody-mediated targeting and CARNK approach show a promising response against various hematological malignancies and solid tumors. Few clinical trials are up and running to test the efficacy of these therapies in the tumor (Table 1). Though some therapies showed great promise in vitro and preclinical settings, they failed in different phases of clinical trials. Not only as a monotherapy but NK cell-mediated therapy can also be 
explored in combination with existing cancer therapies. In traditional chemotherapy or radiotherapy, most of the time, resistance is generated. In this setting, the use of NK cell therapy in synergy may overcome that resistance. To date, many activating and inhibitory receptors have been identified, and some of them are also targeted. Still, there are many mysteries about these KIR receptors that are unexplored. Their in-depth knowledge of signaling in NK cells and their targets can give a powerful tool to potentiate the clinical benefits in cancer patients.

\section{Abbreviations}

ADDC, antibody-dependent cellular cytotoxicity; NK, natural killers; HLA, human leukocyte antigen; MHC, major histocompatibility complex; $\mathrm{CD}$, cluster of differentiation; ITAM, immunoreceptor tyrosine-based activation motif; DNAM-1, DNAX accessory molecule-1; $\mathrm{NKG} 2 \mathrm{D} / \mathrm{A} / \mathrm{C}$, natural killer group 2D/2A/2C; DAP10/ 12, DNAX activating protein 10/12; TRAIL, tumour necrosis factor (TNF)-related apoptosis-inducing ligand; ITIM, immunoreceptor tyrosine-based inhibitory motif; TIGIT, T cell immunoglobulin and ITIM-domain; TIM3, T cell immunoglobulin and mucin-domain containing 3; PD1, programmed cell death protein 1; ILR, interleukin-1 receptor; TLR, toll-like receptor; Epcam, epithelial cell adhesion molecule; CAR, chimeric antigen receptors; LAG-3, lymphocyte-activation gene 3; KLRG1, killer cell lectin-like receptor G1; KIR, killer Ig-like receptor.

\section{Funding}

GL received grants from the Department of Biotechnology (Grants numbers, BT/PR15533/MED/30/1616/2015; BT/ PR14156/BRB/10/1515/2016), Swarna Jayanti Fellowship (DST/SJF/LSA-01/2017-18), from Department of Science and Technology, and Science and Engineering Research Board (EMR/2016/007108), Ministry of Science and Technology, Government of India. SK received a Senior Research Fellowship from the Council of Scientific and Industrial Research (CSIR), Government of India. PP received a Senior Research Fellowship from the Department of Biotechnology (DBT), Government of India.

\section{Disclosure}

The authors declare no competing interests.

\section{References}

1. Ma X, Yu H. Global burden of cancer. Yale J Biol Med. 2006;79 (3-4):85-94.

2. Hanahan D, Weinberg Robert A. Hallmarks of cancer: the next generation. Cell. 2011;144(5):646-674. doi:10.1016/j. cell.2011.02.013

3. Guevara-Patiño JA, Turk MJ, Wolchok JD, Houghton AN. Immunity to cancer through immune recognition of altered self: studies with melanoma. Adv Cancer Res. 2003;90:157-177.

4. Jiang $\mathrm{T}$, Shi $\mathrm{T}$, Zhang $\mathrm{H}$, et al. Tumor neoantigens: from basic research to clinical applications. J Hematol Oncol. 2019;12(1):93. doi:10.1186/s13045-019-0787-5

5. Durgeau A, Virk Y, Corgnac S, Mami-Chouaib F. Recent advances in targeting CD8 T-cell immunity for more effective cancer immunotherapy. Front Immunol. 2018;9(14). doi:10.3389/ fimmu.2018.00014

6. Dunn GP, Bruce AT, Ikeda H, Old LJ, Schreiber RD. Cancer immunoediting: from immunosurveillance to tumor escape. Nat Immunol. 2002;3(11):991-998. doi:10.1038/ni1102-991

7. Yaguchi T, Sumimoto H, Kudo-Saito C, et al. The mechanisms of cancer immunoescape and development of overcoming strategies. Int J Hematol. 2011;93(3):294-300. doi:10.1007/s12185-0110799-6

8. Farhood B, Najafi M, Mortezaee K. CD8(+) cytotoxic $\mathrm{T}$ lymphocytes in cancer immunotherapy: a review. $J$ Cell Physiol. 2019;234(6):8509-8521. doi:10.1002/jcp.27782

9. Karmakar S, Lal G. Role of serotonin receptor signaling in cancer cells and anti-tumor immunity. Theranostics. 2021;11 (11):5296-5312. doi:10.7150/thno.55986

10. Paul S, Kulkarni N, Shilpi LG, Lal G. Intratumoral natural killer cells show reduced effector and cytolytic properties and control the differentiation of effector Th1 cells. Oncoimmunology. 2016;5 (12):e1235106. doi:10.1080/2162402X.2016.1235106

11. Muntasell A, Ochoa MC, Cordeiro L, et al. Targeting NK-cell checkpoints for cancer immunotherapy. Curr Opin Immunol. 2017;45:73-81. doi:10.1016/j.coi.2017.01.003

12. Lorenzo-Herrero S, López-Soto A, Sordo-Bahamonde C, Gonzalez-Rodriguez AP, Vitale M, Gonzalez S. NK cell-based immunotherapy in cancer metastasis. Cancers. 2018;11(1):29. doi:10.3390/cancers 11010029

13. Vivier E, Tomasello E, Baratin M, Walzer T, Ugolini S. Functions of natural killer cells. Nat Immunol. 2008;9(5):503-510. doi: $10.1038 /$ ni 1582

14. Huntington ND, Vosshenrich CAJ, Di Santo JP. Developmental pathways that generate natural-killer-cell diversity in mice and humans. Nat Rev Immunol. 2007;7(9):703-714. doi:10.1038/ nri2154

15. Abel AM, Yang C, Thakar MS, Malarkannan S. Natural killer cells: development, maturation, and clinical utilization. Front Immunol. 2018;9:1869. doi:10.3389/fimmu.2018.01869

16. Bozzano F, Marras F, De Maria A. Natural killer cell development and maturation revisited: possible implications of a novel distinct Lin-CD34+DNAM-1brightCXCR4+ cell progenitor. Front Immunol. 2017;8(268). doi:10.3389/fimmu.2017.00268

17. Sun JC, Lanier LL. NK cell development, homeostasis and function: parallels with $\mathrm{CD}^{+}$T cells. Nat Rev Immunol. 2011;11 (10):645-657. doi:10.1038/nri3044

18. Peng H, Jiang X, Chen Y, et al. Liver-resident NK cells confer adaptive immunity in skin-contact inflammation. $J$ Clin Invest. 2013;123(4):1444-1456. doi:10.1172/JCI66381

19. Tian Z, Chen Y, Gao B. Natural killer cells in liver disease. Hepatology. 2013;57(4):1654-1662. doi:10.1002/hep.26115

20. Fu B, Tian Z, Wei H. Subsets of human natural killer cells and their regulatory effects. Immunology. 2014;141(4):483-489. doi:10.1111/imm.12224 
21. O'Sullivan Timothy E, Sun Joseph C, Lanier Lewis L. Natural killer cell memory. Immunity. 2015;43(4):634-645. doi:10.1016/j. immuni.2015.09.013

22. Fehniger TA, Cooper MA. Harnessing NK cell memory for cancer immunotherapy. Trends Immunol. 2016;37(12):877-888. doi:10.1016/j.it.2016.09.005

23. Beaulieu AM. Transcriptional and epigenetic regulation of memory NK cell responses. Immunol Rev. 2021;300(1):125-133. doi:10.1111/imr.12947

24. Forrest C, Gomes A, Reeves M, Male V. NK cell memory to cytomegalovirus: implications for vaccine development. Vaccines (Basel). 2020;8(3). doi:10.3390/vaccines8030394

25. Wight A, Parsons BD, Rahim MMA, Makrigiannis AP. A central role for Ly49 receptors in NK cell memory. J Immunol. 2020;204 (11):2867-2875. doi:10.4049/jimmunol.2000196

26. Long EO, Kim HS, Liu D, Peterson ME, Rajagopalan S. Controlling natural killer cell responses: integration of signals for activation and inhibition. Annu Rev Immunol. 2013;31:227-258. doi:10.1146/annurev-immunol-020711-075005

27. Topham NJ, Hewitt EW. Natural killer cell cytotoxicity: how do they pull the trigger? Immunology. 2009;128(1):7-15. doi:10.1111/j.1365-2567.2009.03123.x

28. Paul S, Lal G. The molecular mechanism of natural killer cells function and its importance in cancer immunotherapy. Front Immunol. 2017;8(1124). doi:10.3389/fimmu.2017.01124

29. Hu W, Wang G, Huang D, Sui M, Xu Y. Cancer immunotherapy based on natural killer cells: current progress and new opportunities. Front Immunol. 2019;10(1205). doi:10.3389/ fimmu.2019.01205

30. Wu S-Y, Fu T, Jiang Y-Z, Shao Z-M. Natural killer cells in cancer biology and therapy. Mol Cancer. 2020;19(1):120. doi:10.1186/ s12943-020-01238-x

31. Wang W, Erbe AK, Hank JA, Morris ZS, Sondel PM. NK cell-mediated antibody-dependent cellular cytotoxicity in cancer immunotherapy. Front Immunol. 2015;6(368). doi:10.3389/ fimmu.2015.00368

32. Sanseviero E. NK cell-Fc receptors advance tumor immunotherapy. J Clin Med. 2019;8(10):1667. doi:10.3390/ jem8101667

33. Perera PY, Lichy JH, Waldmann TA, Perera LP. The role of interleukin-15 in inflammation and immune responses to infection: implications for its therapeutic use. Microbes Infect. 2012;14 (3):247-261. doi:10.1016/j.micinf.2011.10.006

34. Poznanski SM, Lee AJ, Nham T, et al. Combined stimulation with interleukin-18 and interleukin-12 potently induces interleukin-8 production by natural killer cells. J Innate Immun. 2017;9 (5):511-525. doi:10.1159/000477172

35. Alter G, Malenfant JM, Altfeld M. CD107a as a functional marker for the identification of natural killer cell activity. $J$ Immunol Methods. 2004;294(1):15-22. doi:10.1016/j. jim.2004.08.008

36. Krebs P, Barnes MJ, Lampe K, et al. NK-cell-mediated killing of target cells triggers robust antigen-specific T-cell-mediated and humoral responses. Blood. 2009;113(26):6593-6602. doi:10.1182/blood-2009-01-201467

37. Pardo J, Balkow S, Anel A, Simon MM. Granzymes are essential for natural killer cell-mediated and perf-facilitated tumor control. Eur $J$ Immunol. 2002;32(10):2881-2886. doi:10.1002/1521-4141(2002010)32:10<2881::AID-IMMU2881>3.0.CO;2-K

38. Sonar S, Lal G. Role of tumor necrosis factor superfamily in neuroinflammation and autoimmunity. Front Immunol. 2015;6 (364). doi:10.3389/fimmu.2015.00364

39. Screpanti V, Wallin RPA, Ljunggren H-G, Grandien A. A central role for death receptor-mediated apoptosis in the rejection of tumors by NK cells. J Immunol. 2001;167(4):2068-2073. doi:10.4049/jimmunol.167.4.2068
40. Thorburn A. Death receptor-induced cell killing. Cell Signal. 2004;16(2):139-144. doi:10.1016/j.cellsig.2003.08.007

41. Cheent K, Khakoo SI. Natural killer cells: integrating diversity with function. Immunology. 2009;126(4):449-457. doi:10.1111/ j.1365-2567.2009.03045.x

42. Wensveen FM, Jelenčić V, Polić B. NKG2D: a master regulator of immune cell responsiveness. Front Immunol. 2018;9(441). doi:10.3389/fimmu.2018.00441

43. Bauer S, Groh V, Wu J, et al. Activation of NK cells and T cells by NKG2D, a receptor for stress-inducible MICA. Science. 1999;285(5428):727-729. doi:10.1126/science.285.5428.727

44. Jinushi M, Takehara T, Tatsumi T, et al. Expression and role of MICA and MICB in human hepatocellular carcinomas and their regulation by retinoic acid. Int $J$ Cancer. 2003;104(3):354-361. doi:10.1002/ijc. 10966

45. Groh V, Bahram S, Bauer S, Herman A, Beauchamp M, Spies T. Cell stress-regulated human major histocompatibility complex class I gene expressed in gastrointestinal epithelium. Proc Natl Acad Sci. 1996;93(22):12445-12450. doi:10.1073/pnas.93.22.12445

46. Romanski A, Bug G, Becker S, et al. Mechanisms of resistance to natural killer cell-mediated cytotoxicity in acute lymphoblastic leukemia. Exp Hematol. 2005;33(3):344-352. doi:10.1016/j. exphem.2004.11.006

47. Sconocchia G, Lau M, Provenzano M, et al. The antileukemia effect of HLA-matched NK and NK-T cells in chronic myelogenous leukemia involves NKG2D-target-cell interactions. Blood. 2005;106(10):3666-3672. doi:10.1182/blood-2005-02-0479

48. Carbone E, Neri P, Mesuraca M, et al. HLA class I, NKG2D, and natural cytotoxicity receptors regulate multiple myeloma cell recognition by natural killer cells. Blood. 2005;105(1):251-258. doi:10.1182/blood-2004-04-1422

49. Salih HR, Antropius H, Gieseke F, et al. Functional expression and release of ligands for the activating immunoreceptor NKG2D in leukemia. Blood. 2003;102(4):1389-1396. doi:10.1182/blood2003-01-0019

50. Pende D, Sivori S, Accame L, et al. HLA-G recognition by human natural killer cells. Involvement of CD94 both as inhibitory and as activating receptor complex. Eur J Immunol. 1997;27 (8):1875-1880. doi:10.1002/eji.1830270809

51. Girardi M, Oppenheim DE, Steele CR, et al. Regulation of cutaneous malignancy by $\gamma \delta \mathrm{T}$ cells. Science. 2001;294 (5542):605-609. doi:10.1126/science.1063916

52. Smyth MJ, Swann J, Kelly JM, et al. NKG2D recognition and perforin effector function mediate effective cytokine immunotherapy of cancer. $J$ Exp Med. 2004;200(10):1325-1335. doi:10.1084/ jem.20041522

53. Lowin-Kropf B, Kunz B, Schneider P, Held W. A role for the src family kinase Fyn in NK cell activation and the formation of the repertoire of Ly49 receptors. Eur J Immunol. 2002;32 (3):773-782. doi:10.1002/1521-4141(200203)32:3<773::AIDIMMU773>3.0.CO;2-U

54. Coudert JD, Held W. The role of the NKG2D receptor for tumor immunity. Semin Cancer Biol. 2006;16(5):333-343. doi:10.1016/ j.semcancer.2006.07.008

55. Schenkel AR, Kingry LC, Slayden RA. The ly49 gene family. A brief guide to the nomenclature, genetics, and role in intracellular infection. Front Immunol. 2013;4:90. doi:10.3389/ fimmu.2013.00090

56. Smith HRC, Heusel JW, Mehta IK, et al. Recognition of a virus-encoded ligand by a natural killer cell activation receptor. Proc Natl Acad Sci. 2002;99(13):8826-8831. doi:10.1073/pnas.092258599

57. Silver ET, Gong D-E, Hazes B, Kane KP. Ly-49W, an activating receptor of nonobese diabetic mice with close homology to the inhibitory receptor $\mathrm{Ly}-49 \mathrm{G}$, recognizes $\mathrm{H}-2 \mathrm{D}^{\mathrm{k}}$ and $\mathrm{H}-2 \mathrm{D}^{\mathrm{d}}$. $J$ Immunol. 2001;166(4):2333-2341. doi:10.4049/jimmunol. 166.4.2333 
58. Silver ET, Gong D-E, Chang CS, Amrani A, Santamaria P, Kane KP. Ly-49P activates NK-mediated lysis by recognizing $\mathrm{H}-2 \mathrm{D}^{\mathrm{d} 1}$. J Immunol. 2000;165(4):1771-1781. doi:10.4049/ jimmunol.165.4.1771

59. Nakamura MC, Linnemeyer PA, Niemi EC, et al. Mouse Ly-49D recognizes $\mathrm{H}-2 \mathrm{Dd}$ and activates natural killer cell cytotoxicity. J Exp Med. 1999;189(3):493-500. doi:10.1084/jem.189.3.493

60. Merck E, Voyle RB, MacDonald HR. Ly49D engagement on $\mathrm{T}$ lymphocytes induces TCR-independent activation and CD8 effector functions that control tumor growth. $J$ Immunol. 2009;182(1):183-192. doi:10.4049/jimmunol.182.1.183

61. Gao J-X, Liu X, Wen J, et al. Two-signal requirement for activation and effector function of natural killer cell response to allogeneic tumor cells. Blood. 2004;102:4456-4463. doi:10.1182/ blood-2003-07-2480

62. Shimasaki N, Jain A, Campana D. NK cells for cancer immunotherapy. Nat Rev Drug Discov. 2020;19(3):200-218. doi:10.1038/s41573-019-0052-1

63. Vaidya SV, Stepp SE, McNerney ME, et al. Targeted disruption of the 2B4 gene in mice reveals an in vivo role of 2B4 (CD244) in the rejection of B16 melanoma cells. $J$ Immunol. 2005;174 (2):800-807. doi:10.4049/jimmunol.174.2.800

64. Lee K-M, McNerney ME, Stepp SE, et al. 2B4 acts as a nonmajor histocompatibility complex binding inhibitory receptor on mouse natural killer cells. J Exp Med. 2004;199(9):1245-1254. doi:10.1084/jem.20031989

65. Tangye SG, Cherwinski H, Lanier LL, Phillips JH. 2B4-mediated activation of human natural killer cells. Mol Immunol. 2000;37 (9):493-501. doi:10.1016/S0161-5890(00)00076-6

66. Tangye SG, Lazetic S, Woollatt E, Sutherland GR, Lanier LL, Phillips JH. Cutting edge: human 2B4, an activating NK cell receptor, recruits the protein tyrosine phosphatase SHP-2 and the adaptor signaling protein SAP. J Immunol. 1999;162 (12):6981-6985.

67. Barrow $\mathrm{AD}$, Martin $\mathrm{CJ}$, Colonna M. The natural cytotoxicity receptors in health and disease. Front Immunol. 2019;10:909. doi:10.3389/fimmu.2019.00909

68. Pogge von Strandmann E, Shatnyeva O, Hansen HP. NKp30 and its ligands: emerging players in tumor immune evasion from natural killer cells. Ann Transl Med. 2015;3(20):2305-5839.

69. Brandt CS, Baratin M, Yi EC, et al. The B7 family member B7-H6 is a tumor cell ligand for the activating natural killer cell receptor NKp30 in humans. J Exp Med. 2009;206(7):1495-1503. doi:10.1084/jem.20090681

70. Töpfer K, Cartellieri M, Michen S, et al. DAP12-based activating chimeric antigen receptor for NK cell tumor immunotherapy. $J$ Immunol. 2015;194(7):3201-3212. doi:10.4049/jimmunol. 1400330

71. Li Y, Hermanson DL, Moriarity BS, Kaufman DS. Human iPSC-derived natural killer cells engineered with chimeric antigen receptors enhance anti-tumor activity. Cell Stem Cell. 2018;23 (2):181-192. doi:10.1016/j.stem.2018.06.002

72. Rah S-Y, Kwak J-Y, Chung Y-J, Kim U-H. ADP-ribose/TRPM2mediated $\mathrm{Ca} 2+$ signaling is essential for cytolytic degranulation and antitumor activity of natural killer cells. Sci Rep. 2015;5 (1):9482. doi:10.1038/srep09482

73. Mallone R, Funaro A, Zubiaur M, et al. Signaling through CD38 induces NK cell activation. Int Immunol. 2001;13(4):397-409. doi:10.1093/intimm/13.4.397

74. Pegram HJ, Andrews DM, Smyth MJ, Darcy PK, Kershaw MH. Activating and inhibitory receptors of natural killer cells. Immunol Cell Biol. 2011;89(2):216-224. doi:10.1038/icb.2010.78

75. Lakshmikanth T, Burke S, Ali TH, et al. NCRs and DNAM-1 mediate NK cell recognition and lysis of human and mouse melanoma cell lines in vitro and in vivo. $J$ Clin Invest. 2009;119(5):1251-1263. doi:10.1172/JCI36022
76. Sanchez-Correa B, Morgado S, Gayoso I, et al. Human NK cells in acute myeloid leukaemia patients: analysis of NK cell-activating receptors and their ligands. Cancer Immunol Immunother. 2011;60(8):1195-1205. doi:10.1007/s00262-011$1050-2$

77. Mamessier E, Sylvain A, Bertucci F, et al. Human breast tumor cells induce self-tolerance mechanisms to avoid NKG2D-mediated and DNAM-mediated NK cell recognition. Cancer Res. 2011;71(21):6621-6632. doi:10.1158/0008-5472. CAN-11-0792

78. Mirjačić Martinović KM, Babović N, Džodić RR, Jurišić VB, Tanić NT, Konjević GM. Decreased expression of NKG2D, NKp46, DNAM-1 receptors, and intracellular perforin and STAT-1 effector molecules in NK cells and their dim and bright subsets in metastatic melanoma patients. Melanoma Res. 2014;24(4):295-304. doi:10.1097/CMR.0000000 000000072

79. Zhang $\mathrm{C}, \mathrm{Hu} \mathrm{Y}$, Shi $\mathrm{C}$. Targeting natural killer cells for tumor immunotherapy. Front Immunol. 2020;11:60.

80. Balsamo M, Scordamaglia F, Pietra G, et al. Melanomaassociated fibroblasts modulate NK cell phenotype and antitumor cytotoxicity. Proc Natl Acad Sci U $\quad S$ A. 2009;106 (49):20847-20852. doi:10.1073/pnas.0906481106

81. Lanier LL. Natural killer cell receptor signaling. Curr Opin Immunol. 2003;15(3):308-314. doi:10.1016/S0952-7915(03) 00039-6

82. Metes D, Ernst LK, Chambers WH, Sulica A, Herberman RB, Morel PA. Expression of functional CD32 molecules on human NK cells is determined by an allelic polymorphism of the FcgammaRIIC gene. Blood. 1998;91(7):2369-2380. doi:10.1182/blood.V91.7.2369

83. Ernst LK, Metes D, Herberman RB, Morel PA. Allelic polymorphisms in the FcgammaRIIC gene can influence its function on normal human natural killer cells. J Mol Med. 2002;80 (4):248-257. doi:10.1007/s00109-001-0294-2

84. Karre K, Ljunggren HG, Piontek G, Kiessling R. Selective rejection of H-2-deficient lymphoma variants suggests alternative immune defence strategy. Nature. 1986;319(6055):675-678. doi:10.1038/319675a0

85. Ljunggren HG, Karre K. In search of the 'missing self': MHC molecules and NK cell recognition. Immunol Today. 1990;11 (7):237-244. doi:10.1016/0167-5699(90)90097-s

86. Kumar S. Natural killer cell cytotoxicity and its regulation by inhibitory receptors. Immunology. 2018;154(3):383-393. doi:10.1111/imm.12921

87. Long EO. Negative signaling by inhibitory receptors: the NK cell paradigm. Immunol Rev. 2008;224:70-84. doi:10.1111/j.1600065X.2008.00660.X

88. Rajasekaran K, Riese MJ, Rao S, et al. Signaling in effector lymphocytes: insights toward safer immunotherapy. Front Immunol. 2016;7:176. doi:10.3389/fimmu.2016.00176

89. Sivori S, Vacca P, Del Zotto G, Munari E, Mingari MC, Moretta L. Human NK cells: surface receptors, inhibitory checkpoints, and translational applications. Cell Mol Immunol. 2019;16 (5):430-441. doi:10.1038/s41423-019-0206-4

90. Vilches C, Parham P. KIR: diverse, rapidly evolving receptors of innate and adaptive immunity. Annu Rev Immunol. 2002;20:217-251. doi:10.1146/annurev.immunol.20.092501.134942

91. Braud VM, Allan DS, O'Callaghan CA, et al. HLA-E binds to natural killer cell receptors CD94/NKG2A, B and C. Nature. 1998;391(6669):795-799. doi:10.1038/35869

92. Moretta L. Dissecting CD56dim human NK cells. Blood. 2010;116(19):3689-3691. doi:10.1182/blood-2010-09-303057

93. Cheng M, Chen Y, Xiao W, Sun R, Tian Z. NK cell-based immunotherapy for malignant diseases. Cell Mol Immunol. 2013;10(3):230-252. doi:10.1038/cmi.2013.10 
94. Andre P, Denis C, Soulas C, et al. Anti-NKG2A mAb is a checkpoint inhibitor that promotes anti-tumor immunity by unleashing both T and NK cells. Cell. 2018;175(7):1731-1743 e13. doi:10.1016/j.cell.2018.10.014

95. Mingari MC, Ponte M, Bertone S, et al. HLA class I-specific inhibitory receptors in human $\mathrm{T}$ lymphocytes: interleukin 15-induced expression of CD94/NKG2A in superantigen- or alloantigen-activated CD8+ T cells. Proc Natl Acad Sci USA. 1998;95(3):1172-1177. doi:10.1073/pnas.95.3.1172

96. Bertone S, Schiavetti F, Bellomo R, et al. Transforming growth factor-beta-induced expression of CD94/NKG2A inhibitory receptors in human T lymphocytes. Eur J Immunol. 1999;29 (1):23-29. doi:10.1002/(SICI)1521-4141(199901)29:01<23:: AID-IMMU23>3.0.CO;2-Y

97. Caligiuri MA. Human natural killer cells. Blood. 2008;112 (3):461-469. doi:10.1182/blood-2007-09-077438

98. Hammer Q, Ruckert T, Borst EM, et al. Peptide-specific recognition of human cytomegalovirus strains controls adaptive natural killer cells. Nat Immunol. 2018;19(5):453-463. doi:10.1038/ s41590-018-0082-6

99. Della Chiesa M, Sivori S, Carlomagno S, Moretta L, Moretta A. Activating KIRs and $\mathrm{NKG} 2 \mathrm{C}$ in viral infections: toward NK cell memory? Front Immunol. 2015;6:573. doi:10.3389/ fimmu.2015.00573

100. Colonna M, Navarro F, Bellon T, et al. A common inhibitory receptor for major histocompatibility complex class I molecules on human lymphoid and myelomonocytic cells. J Exp Med. 1997;186(11):1809-1818. doi:10.1084/jem.186.11.1809

101. Ponte M, Cantoni C, Biassoni R, et al. Inhibitory receptors sensing HLA-G1 molecules in pregnancy: decidua-associated natural killer cells express LIR-1 and CD94/NKG2A and acquire p49, an HLA-G1-specific receptor. Proc Natl Acad Sci U S A. 1999;96 (10):5674-5679. doi:10.1073/pnas.96.10.5674

102. Cosman D, Fanger N, Borges L, et al. A novel immunoglobulin superfamily receptor for cellular and viral MHC class I molecules. Immunity. 1997;7(2):273-282. doi:10.1016/s10747613(00)80529-4

103. Vitale M, Castriconi R, Parolini S, et al. The leukocyte Ig-like receptor (LIR)-1 for the cytomegalovirus UL18 protein displays a broad specificity for different HLA class I alleles: analysis of LIR-1 + NK cell clones. Int Immunol. 1999;11(1):29-35. doi:10.1093/intimm/11.1.29

104. Muccio L, Bertaina A, Falco M, et al. Analysis of memory-like natural killer cells in human cytomegalovirus-infected children undergoing alphabeta $+\mathrm{T}$ and $\mathrm{B}$ cell-depleted hematopoietic stem cell transplantation for hematological malignancies. Haematologica. 2016;101(3):371-381. doi:10.3324/ haematol.2015.134155

105. Fong JJ, Tsai CM, Saha S, Nizet V, Varki A, Bui JD. Siglec-7 engagement by GBS beta-protein suppresses pyroptotic cell death of natural killer cells. Proc Natl Acad Sci U S A. 2018;115 (41):10410-10415. doi:10.1073/pnas.1804108115

106. Murakami Y, Tian L, Voss OH, Margulies DH, Krzewski K, Coligan JE. CD300b regulates the phagocytosis of apoptotic cells via phosphatidylserine recognition. Cell Death Differ. 2014;21(11):1746-1757. doi:10.1038/cdd.2014.86

107. Sivori S, Della Chiesa M, Carlomagno S, et al. Inhibitory receptors and checkpoints in human NK cells, implications for the immunotherapy of cancer. Front Immunol. 2020;11:2156. doi:10.3389/fimmu.2020.02156

108. Ferris RL, Jaffee EM, Ferrone S. Tumor antigen-targeted, monoclonal antibody-based immunotherapy: clinical response, cellular immunity, and immunoescape. J Clin Oncol. 2010;28 (28):4390-4399. doi:10.1200/JCO.2009.27.6360
109. Felices M, Lenvik TR, Davis ZB, Miller JS, Vallera DA. Generation of BiKEs and TriKEs to improve NK cell-mediated targeting of tumor cells. Methods Mol Biol. 2016;1441:3684728.

110. Chan WK, Kang S, Youssef Y, et al. A CS1-NKG2D bispecific antibody collectively activates cytolytic immune cells against multiple myeloma. Cancer Immunol Res. 2018;6(7):776-787. doi:10.1158/2326-6066.CIR-17-0649

111. Rothe A, Sasse S, Topp MS, et al. A phase 1 study of the bispecific anti-CD30/CD16A antibody construct AFM13 in patients with relapsed or refractory Hodgkin lymphoma. Blood. 2015;125(26):4024-4031. doi:10.1182/blood-2014-12-614636

112. Wu J, Fu J, Zhang M, Liu D. AFM13: a first-in-class tetravalent bispecific anti-CD30/CD16A antibody for NK cell-mediated immunotherapy. J Hematol Oncol. 2015;8(1):96. doi:10.1186/ s13045-015-0188-3

113. Pahl JHW, Koch J, Götz JJ, et al. CD16A activation of NK cells promotes NK cell proliferation and memory-like cytotoxicity against cancer cells. Cancer Immunol Res. 2018;6(5):517-527. doi:10.1158/2326-6066.CIR-17-0550

114. Davis ZB, Vallera DA, Miller JS, Felices M. Natural killer cells unleashed: checkpoint receptor blockade and BiKE/TriKE utilization in NK-mediated anti-tumor immunotherapy. Semin Immunol. 2017;31:64-75. doi:10.1016/j.smim.2017.07.011

115. Felices M, Kodal B, Hinderlie P, et al. Novel CD19-targeted TriKE restores NK cell function and proliferative capacity in CLL. Blood Adv. 2019;3(6):897-907. doi:10.1182/ bloodadvances.2018029371

116. Vallera DA, Felices M, McElmurry R, et al. IL15 trispecific killer engagers (TriKE) make natural killer cells specific to $\mathrm{CD} 33+$ targets while also inducing persistence, in vivo expansion, and enhanced function. Clin Cancer Res. 2016;22(14):3440-3450. doi:10.1158/1078-0432.CCR-15-2710

117. Schmohl JU, Felices M, Taras E, Miller JS, Vallera DA. Enhanced ADCC and NK cell activation of an anticarcinoma bispecific antibody by genetic insertion of a modified IL-15 cross-linker. Mol Ther. 2016;24(7):1312-1322. doi:10.1038/ mt.2016.88

118. Gauthier L, Morel A, Anceriz N, et al. Multifunctional natural killer cell engagers targeting NKp46 trigger protective tumor immunity. Cell. 2019;177(7):1701-1713. doi:10.1016/j. cell.2019.04.041

119. Chester C, Sanmamed MF, Wang J, Melero I. Immunotherapy targeting 4-1BB: mechanistic rationale, clinical results, and future strategies. Blood. 2018;131(1):49-57. doi:10.1182/blood-2017-06-741041

120. Segal NH, Logan TF, Hodi FS, et al. Results from an integrated safety analysis of urelumab, an agonist anti-CD137 monoclonal antibody. Clin Cancer Res. 2017;23(8):1929-1936. doi:10.1158/ 1078-0432.CCR-16-1272

121. Segal NH, He AR, Doi T, et al. Phase I study of single-agent utomilumab (PF-05082566), a 4-1BB/CD137 agonist, in patients with advanced cancer. Clin Cancer Res. 2018;24(8):1816-1823. doi:10.1158/1078-0432.CCR-17-1922

122. Ferrari de Andrade L, Tay RE, Pan D, et al. Antibody-mediated inhibition of MICA and MICB shedding promotes NK cell-driven tumor immunity. Science. 2018;359(6383):1537-1542. doi:10.1126/science.aao0505

123. Geller MA, Miller JS. Use of allogeneic NK cells for cancer immunotherapy. Immunotherapy. 2011;3(12):1445-1459. doi:10.2217/imt.11.131

124. Ruggeri L, Capanni M, Urbani E, et al. Effectiveness of donor natural killer cell alloreactivity in mismatched hematopoietic transplants. Science. 2002;295(5562):2097-2100. doi:10.1126/ science. 1068440 
125. Calvo T, Reina-Ortiz C, Giraldos D, et al. Expanded and activated allogeneic NK cells are cytotoxic against B-chronic lymphocytic leukemia (B-CLL) cells with sporadic cases of resistance. Sci Rep. 2020;10(1):19398. doi:10.1038/s41598-020-76051-z

126. Miller JS, Soignier Y, Panoskaltsis-Mortari A, et al. Successful adoptive transfer and in vivo expansion of human haploidentical NK cells in patients with cancer. Blood. 2005;105(8):3051-3057. doi:10.1182/blood-2004-07-2974

127. Prlic M, Blazar BR, Farrar MA, Jameson SC. In vivo survival and homeostatic proliferation of natural killer cells. J Exp Med. 2003;197(8):967-976. doi:10.1084/jem.20021847

128. Fehniger TA, Caligiuri MA. Ontogeny and expansion of human natural killer cells: clinical implications. Int Rev Immunol. 2001;20(3-4):503-534. doi:10.3109/08830180109054417

129. Geller MA, Cooley S, Judson PL, et al. A phase II study of allogeneic natural killer cell therapy to treat patients with recurrent ovarian and breast cancer. Cytotherapy. 2011;13(1):98-107. doi:10.3109/14653249.2010.515582

130. Klingemann H. Are natural killer cells superior CAR drivers? Oncoimmunology. 2014;15(3):e28147.

131. Hu Y, Tian ZG, Zhang C. Chimeric antigen receptor (CAR)-transduced natural killer cells in tumor immunotherapy. Acta Pharmacol Sin. 2018;39(2):167-176. doi:10.1038/aps.2017.125

132. Oei VYS, Siernicka M, Graczyk-Jarzynka A, et al. Intrinsic functional potential of NK-cell subsets constrains retargeting driven by chimeric antigen receptors. Cancer Immunol Res. 2018;6 (4):467-480. doi:10.1158/2326-6066.CIR-17-0207

133. Zhuang $\mathrm{X}$, Long EO. CD28 homolog is a strong activator of natural killer cells for lysis of $\mathrm{B} 7 \mathrm{H} 7(+)$ tumor cells. Cancer Immunol Res. 2019;7(6):939-951.

134. Marofi F, Saleh MM, Rahman HS, et al. CAR-engineered NK cells; a promising therapeutic option for treatment of hematological malignancies. Stem Cell Res Ther. 2021;12(1):374. doi:10.1186/s13287-021-02462-y

135. Wilson MH, Coates CJ, George AL. PiggyBac transposon-mediated gene transfer in human cells. Mol Ther. 2007;15(1):139-145. doi:10.1038/sj.mt.6300028

136. Wang J, Lupo KB, Chambers AM, Matosevic S. Purinergic targeting enhances immunotherapy of $\mathrm{CD} 73(+)$ solid tumors with piggyBac-engineered chimeric antigen receptor natural killer cells. J Immunother Cancer. 2018;6(1):018-0441. doi:10.1186/ s40425-018-0441-8

137. Chang YH, Connolly J, Shimasaki N, Mimura K, Kono K, Campana D. A chimeric receptor with NKG2D specificity enhances natural killer cell activation and killing of tumor cells. Cancer Res. 2013;73(6):1777-1786. doi:10.1158/0008-5472.CAN-12-3558

138. Parihar R, Rivas C, Huynh M, et al. NK cells expressing a chimeric activating receptor eliminate MDSCs and rescue impaired CAR-T cell activity against solid tumors. Cancer Immunol Res. 2019;7(3):363-375. doi:10.1158/2326-6066.CIR18-0572

139. Liu E, Tong Y, Dotti G, et al. Cord blood NK cells engineered to express IL-15 and a CD19-targeted CAR show long-term persistence and potent antitumor activity. Leukemia. 2018;32 (2):520-531. doi:10.1038/leu.2017.226

140. Imai C, Iwamoto S, Campana D. Genetic modification of primary natural killer cells overcomes inhibitory signals and induces specific killing of leukemic cells. Blood. 2005;106(1):376-383. doi:10.1182/blood-2004-12-4797

141. Li L, Liu LN, Feller S, et al. Expression of chimeric antigen receptors in natural killer cells with a regulatory-compliant non-viral method. Cancer Gene Ther. 2010;17(3):147-154. doi:10.1038/cgt.2009.61

142. Rezvani K, Rouce R, Liu E, Shpall E. Engineering natural killer cells for cancer immunotherapy. Mol Ther. 2017;25 (8):1769-1781. doi:10.1016/j.ymthe.2017.06.012
143. Matosevic S. Viral and nonviral engineering of natural killer cells as emerging adoptive cancer immunotherapies. J Immunol Res. 2018;17:4054815. doi:10.1155/2018/4054815

144. Woll PS, Grzywacz B, Tian X, et al. Human embryonic stem cells differentiate into a homogeneous population of natural killer cells with potent in vivo antitumor activity. Blood. 2009;113 (24):6094-6101. doi:10.1182/blood-2008-06-165225

145. Knorr DA, Bock A, Brentjens RJ, Kaufman DS. Engineered human embryonic stem cell-derived lymphocytes to study in vivo trafficking and immunotherapy. Stem Cells Dev. 2013;22 (13):1861-1869. doi:10.1089/scd.2012.0608

146. Knorr DA, Ni Z, Hermanson D, et al. Clinical-scale derivation of natural killer cells from human pluripotent stem cells for cancer therapy. Stem Cells Transl Med. 2013;2(4):274-283. doi:10.5966/ sctm.2012-0084

147. Gornalusse GG, Hirata RK, Funk SE, et al. HLA-E-expressing pluripotent stem cells escape allogeneic responses and lysis by NK cells. Nat Biotechnol. 2017;35(8):765-772. doi:10.1038/nbt.3860

148. Xie G, Dong H, Liang Y, Ham JD, Rizwan R, Chen J. CAR-NK cells: a promising cellular immunotherapy for cancer. EBioMedicine. 2020;59(102975):24. doi:10.1016/j.ebiom.2020.102975

149. Bryceson YT, March ME, Ljunggren HG, Long EO. Synergy among receptors on resting NK cells for the activation of natural cytotoxicity and cytokine secretion. Blood. 2006;107(1):159-166. doi:10.1182/blood-2005-04-1351

150. Leong JW, Chase JM, Romee R, et al. Preactivation with IL-12, IL-15, and IL-18 induces CD25 and a functional high-affinity IL-2 receptor on human cytokine-induced memory-like natural killer cells. Biol Blood Marrow Transplant. 2014;20(4):463-473. doi:10.1016/j.bbmt.2014.01.006

151. Romee R, Rosario M, Berrien-Elliott MM, et al. Cytokineinduced memory-like natural killer cells exhibit enhanced responses against myeloid leukemia. Sci Transl Med. 2016;8 (357). doi:10.1126/scitranslmed.aaf2341.

152. Ni J, Miller M, Stojanovic A, Garbi N, Cerwenka A. Sustained effector function of IL-12/15/18-preactivated NK cells against established tumors. $J$ Exp Med. 2012;209(13):2351-2365. doi:10.1084/jem.20120944

153. Cichocki F, Valamehr B, Bjordahl R, et al. GSK3 inhibition drives maturation of NK cells and enhances their antitumor activity. Cancer Res. 2017;77(20):5664-5675. doi:10.1158/0008-5472.CAN-17-0799

154. North J, Bakhsh I, Marden C, et al. Tumor-primed human natural killer cells lyse NK-resistant tumor targets: evidence of a two-stage process in resting $\mathrm{NK}$ cell activation. $J$ Immunol. 2007;178(1):85-94. doi:10.4049/jimmunol.178.1.85

155. Fehniger TA, Miller JS, Stuart RK, et al. A phase 1 trial of CNDO-109-activated natural killer cells in patients with high-risk acute myeloid leukemia. Biol Blood Marrow Transplant. 2018;24 (8):1581-1589. doi:10.1016/j.bbmt.2018.03.019

156. Cornel AM, Mimpen IL, Nierkens S. MHC class I downregulation in cancer: underlying mechanisms and potential targets for cancer immunotherapy. Cancers (Basel). 2020;12 (7):1760. doi:10.3390/cancers12071760

157. van Montfoort N, Borst L, Korrer MJ, et al. NKG2A blockade potentiates CD8 $\mathrm{T}$ cell immunity induced by cancer vaccines. Cell. 2018;175(7):1744-1755 e15. doi:10.1016/j.cell.2018.10.028

158. van Hall T, Andre P, Horowitz A, et al. Monalizumab: inhibiting the novel immune checkpoint NKG2A. J Immunother Cancer. 2019;7(1):263. doi:10.1186/s40425-019-0761-3

159. Graydon CG, Mohideen S, Fowke KR. LAG3's enigmatic mechanism of action. Front Immunol. 2020;11:615317. doi:10.3389/fimmu.2020.615317

160. Lichtenegger FS, Rothe M, Schnorfeil FM, et al. Targeting LAG-3 and PD-1 to enhance $\mathrm{T}$ cell activation by antigen-presenting cells. Front Immunol. 2018;9:385. doi:10.3389/fimmu.2018.00385 
161. Woo SR, Turnis ME, Goldberg MV, et al. Immune inhibitory molecules LAG-3 and PD-1 synergistically regulate T-cell function to promote tumoral immune escape. Cancer Res. 2012;72 (4):917-927. doi:10.1158/0008-5472.CAN-11-1620

162. Morandi F, Rizzo R, Fainardi E, Rouas-Freiss N, Pistoia V. Recent advances in our understanding of HLA-G biology: lessons from a wide spectrum of human diseases. $J$ Immunol Res. 2016;2016:4326495. doi:10.1155/2016/4326495

163. Anna F, Bole-Richard E, LeMaoult J, et al. First immunotherapeutic CAR-T cells against the immune checkpoint protein HLA-G. J Immunother Cancer. 2021;9(3):e001998. doi:10.1136/ jitc-2020-001998

164. Locatelli F, Pende D, Falco M, Della Chiesa M, Moretta A, Moretta L. NK cells mediate a crucial graft-versus-leukemia effect in haploidentical-HSCT to cure high-risk acute leukemia. Trends Immunol. 2018;39(7):577-590. doi:10.1016/j.it.2018.04.009

165. Pende D, Marcenaro S, Falco M, et al. Anti-leukemia activity of alloreactive NK cells in KIR ligand-mismatched haploidentical HSCT for pediatric patients: evaluation of the functional role of activating KIR and redefinition of inhibitory KIR specificity. Blood. 2009;113(13):3119-3129. doi:10.1182/blood-2008-06-164103

166. Curti A, Ruggeri L, D'Addio A, et al. Successful transfer of alloreactive haploidentical KIR ligand-mismatched natural killer cells after infusion in elderly high risk acute myeloid leukemia patients. Blood. 2011;118(12):3273-3279. doi:10.1182/blood-2011-01-329508

167. Cooley S, Weisdorf DJ, Guethlein LA, et al. Donor selection for natural killer cell receptor genes leads to superior survival after unrelated transplantation for acute myelogenous leukemia. Blood. 2010;116(14):2411-2419. doi:10.1182/blood-2010-05-283051

168. Weisdorf D, Cooley S, Wang T, et al. KIR B donors improve the outcome for AML patients given reduced intensity conditioning and unrelated donor transplantation. Blood Adv. 2020;4 (4):740-754. doi:10.1182/bloodadvances.2019001053

169. Bagot M, Porcu P, Marie-Cardine A, et al. IPH4102, a first-inclass anti-KIR3DL2 monoclonal antibody, in patients with relapsed or refractory cutaneous T-cell lymphoma: an international, first-in-human, open-label, phase 1 trial. Lancet Oncol. 2019;20(8):1160-1170. doi:10.1016/S1470-2045(19)30320-1

170. Venstrom JM, Zheng J, Noor N, et al. KIR and HLA genotypes are associated with disease progression and survival following autologous hematopoietic stem cell transplantation for high-risk neuroblastoma. Clin Cancer Res. 2009;15(23):7330-7334. doi:10.1158/1078-0432.CCR-09-1720

171. Tarek N, Le Luduec JB, Gallagher MM, et al. Unlicensed NK cells target neuroblastoma following anti-GD2 antibody treatment. J Clin Invest. 2012;122(9):3260-3270. doi:10.1172/JCI62749

172. Erbe AK, Wang W, Carmichael L, et al. Follicular lymphoma patients with KIR2DL2 and KIR3DL1 and their ligands (HLA-C1 and HLA-Bw4) show improved outcome when receiving rituximab. J Immunother Cancer. 2019;7(1):70. doi:10.1186/ s40425-019-0538-8

173. Erbe AK, Wang W, Carmichael L, et al. Neuroblastoma patients' KIR and KIR-ligand genotypes influence clinical outcome for dinutuximab-based immunotherapy: a report from the children's oncology group. Clin Cancer Res. 2018;24(1):189-196. doi:10.1158/1078-0432.CCR-17-1767

174. Pesce S, Greppi M, Tabellini G, et al. Identification of a subset of human natural killer cells expressing high levels of programmed death 1: a phenotypic and functional characterization. $J$ Allergy Clin Immunol. 2017;139(1):335-346e3. doi:10.1016/j. jaci.2016.04.025

175. Liu Y, Cheng Y, Xu Y, et al. Increased expression of programmed cell death protein 1 on NK cells inhibits NK-cell-mediated anti-tumor function and indicates poor prognosis in digestive cancers. Oncogene. 2017;36(44):6143-6153. doi:10.1038/ onc.2017.209
176. Beldi-Ferchiou A, Lambert M, Dogniaux S, et al. PD-1 mediates functional exhaustion of activated NK cells in patients with Kaposi sarcoma. Oncotarget. 2016;7(45):72961-72977. doi:10.18632/oncotarget.12150

177. Benson DM, Bakan CE, Mishra A, et al. The PD-1/PD-L1 axis modulates the natural killer cell versus multiple myeloma effect: a therapeutic target for CT-011, a novel monoclonal anti-PD-1 antibody. Blood. 2010;116(13):2286-2294. doi:10.1182/blood2010-02-271874

178. Quatrini L, Vacca P, Tumino N, et al. Glucocorticoids and the cytokines IL-12, IL-15, and IL-18 present in the tumor microenvironment induce PD-1 expression on human natural killer cells. J Allergy Clin Immunol. 2021;147(1):349-360. doi:10.1016/j. jaci.2020.04.044

179. Mariotti FR, Quatrini L, Munari E, et al. Inhibitory checkpoints in human natural killer cells: IUPHAR review 28. Br J Pharmacol. 2020;177(13):2889-2903. doi:10.1111/bph.15081

180. Ribas A, Wolchok JD. Cancer immunotherapy using checkpoint blockade. Science. 2018;359(6382):1350-1355. doi:10.1126/ science.aar 4060

181. Sholl LM, Aisner DL, Allen TC, et al. Programmed death ligand1 immunohistochemistry-a new challenge for pathologists: a perspective from members of the pulmonary pathology society. Arch Pathol Lab Med. 2016;140(4):341-344. doi:10.5858/ arpa.2015-0506-SA

182. Sharpe AH, Pauken KE. The diverse functions of the PD1 inhibitory pathway. Nat Rev Immunol. 2018;18(3):153-167. doi:10.1038/nri.2017.108

183. Acharya N, Sabatos-Peyton C, Anderson AC. Tim-3 finds its place in the cancer immunotherapy landscape. $J$ Immunother Cancer. 2020;8(1):e000911. doi:10.1136/jitc-2020-000911

184. da Silva IP, Gallois A, Jimenez-Baranda S, et al. Reversal of NK-cell exhaustion in advanced melanoma by Tim-3 blockade. Cancer Immunol Res. 2014;2(5):410-422. doi:10.1158/23266066.CIR-13-0171

185. Xu L, Huang $\mathrm{Y}$, Tan $\mathrm{L}$, et al. Increased Tim-3 expression in peripheral NK cells predicts a poorer prognosis and Tim-3 blockade improves NK cell-mediated cytotoxicity in human lung adenocarcinoma. Int Immunopharmacol. 2015;29(2):635-641. doi:10.1016/j.intimp.2015.09.017

186. Zhang Y, Cai P, Liang T, Wang L, Hu L. TIM-3 is a potential prognostic marker for patients with solid tumors: a systematic review and meta-analysis. Oncotarget. 2017;8(19):31705-31713. doi:10.18632/oncotarget.15954

187. Chauvin JM, Zarour HM. TIGIT in cancer immunotherapy. $J$ Immunother Cancer. 2020;8(2):e00957. doi:10.1136/jitc2020-000957

188. Zhang Q, Bi J, Zheng X, et al. Blockade of the checkpoint receptor TIGIT prevents NK cell exhaustion and elicits potent anti-tumor immunity. Nat Immunol. 2018;19(7):723-732. doi:10.1038/s41590-018-0132-0

189. Zhou XM, Li WQ, Wu YH, et al. Intrinsic expression of immune checkpoint molecule TIGIT could help tumor growth in vivo by suppressing the function of $\mathrm{NK}$ and $\mathrm{CD} 8(+) \mathrm{T}$ cells. Front Immunol. 2018;9:2821. doi:10.3389/fimmu.2018.02821

190. Hung AL, Maxwell R, Theodros D, et al. TIGIT and PD-1 dual checkpoint blockade enhances antitumor immunity and survival in GBM. Oncoimmunology. 2018;7(8):e1466769. doi:10.1080/ 2162402X.2018.1466769

191. Shao JY, Yin WW, Zhang QF, et al. Siglec-7 defines a highly functional natural killer cell subset and inhibits cell-mediated activities. Scand J Immunol. 2016;84(3):182-190. doi:10.1111/sji.12455

192. Daly J, Carlsten M, O’Dwyer M. Sugar free: novel immunotherapeutic approaches targeting siglecs and sialic acids to enhance natural killer cell cytotoxicity against cancer. Front Immunol. 2019;10:1047. doi:10.3389/fimmu.2019.01047 
193. Xiao H, Woods EC, Vukojicic P, Bertozzi CR. Precision glycocalyx editing as a strategy for cancer immunotherapy. Proc Natl Acad Sci U S A. 2016;113(37):10304-10309. doi:10.1073/ pnas. 1608069113

194. Macauley MS, Arlian BM, Rillahan CD, et al. Systemic blockade of sialylation in mice with a global inhibitor of sialyltransferases. $J$ Biol Chem. 2014;289(51):35149-35158. doi:10.1074/jbc. M114.606517

195. Bull C, Boltje TJ, Balneger N, et al. Sialic acid blockade suppresses tumor growth by enhancing T-cell-mediated tumor immunity. Cancer Res. 2018;78(13):3574-3588. doi:10.1158/ 0008-5472.CAN-17-3376

196. Meril S, Harush O, Reboh Y, Matikhina T, Barliya T, Cohen CJ. Targeting glycosylated antigens on cancer cells using siglec-7/ 9-based CAR T-cells. Mol Carcinog. 2020;59(7):713-723. doi: $10.1002 / \mathrm{mc} .23213$

197. Molgora M, Supino D, Mantovani A, Garlanda C. Tuning inflammation and immunity by the negative regulators IL-1R2 and IL-1R8. Immunol Rev. 2018;281(1):233-247. doi:10.1111/ imr. 12609

198. Molgora M, Bonavita E, Ponzetta A, et al. IL-1R8 is a checkpoint in NK cells regulating anti-tumour and anti-viral activity. Nature. 2017;551(7678):110-114. doi:10.1038/nature24293

199. Verbrugge A, de Ruiter T, Geest C, Coffer PJ, Meyaard L. Differential expression of leukocyte-associated Ig-like receptor-1 during neutrophil differentiation and activation. $J$ Leukoc Biol. 2006;79(4):828-836. doi:10.1189/jlb.0705370

200. Jansen CA, Cruijsen CW, de Ruiter T, et al. Regulated expression of the inhibitory receptor LAIR-1 on human peripheral $\mathrm{T}$ cells during $\mathrm{T}$ cell activation and differentiation. Eur $J$ Immunol. 2007;37(4):914-924. doi:10.1002/eji.200636678

201. van der Vuurst de Vries AR, Clevers H, Logtenberg $T$, Meyaard L. Leukocyte-associated immunoglobulin-like receptor-1 (LAIR-1) is differentially expressed during human B cell differentiation and inhibits B cell receptor-mediated signaling. Eur J Immunol. 1999;29(10):3160-3167. doi:10.1002/ (SICI)1521-4141(199910)29:10<3160::AID-IMMU3160>3.0 $\mathrm{CO} ; 2-\mathrm{S}$

202. Guo N, Zhang K, Gao X, et al. Role and mechanism of LAIR-1 in the development of autoimmune diseases, tumors, and malaria: a review. Curr Res Transl Med. 2020;68(3):119-124. doi:10.1016/j. retram.2020.05.003

203. Peng DH, Rodriguez BL, Diao L, et al. Collagen promotes anti-PD-1/PD-L1 resistance in cancer through LAIR1-dependent CD8(+) T cell exhaustion. Nat Commun. 2020;11(1):4520. doi:10.1038/s41467-020-18298-8

204. Meyaard L, Adema GJ, Chang C, et al. LAIR-1, a novel inhibitory receptor expressed on human mononuclear leukocytes. Immunity. $\quad$ 1997;7(2):283-290. doi:10.1016/s1074-7613(00) 80530-0
205. Joseph C, Alsaleem MA, Toss MS, et al. The ITIM-containing receptor: leukocyte-associated immunoglobulin-like receptor-1 (LAIR-1) modulates immune response and confers poor prognosis in invasive breast carcinoma. Cancers (Basel). 2020;13 (1):80. doi:10.3390/cancers 13010080

206. Nakamura S, Kuroki K, Ohki I, et al. Molecular basis for E-cadherin recognition by killer cell lectin-like receptor G1 (KLRG1). J Biol Chem. 2009;284(40):27327-27335. doi:10.1074/jbc.M109.038802

207. Miller JS, Lanier LL. Natural killer cells in cancer immunotherapy. Ann Rev Cancer Biol. 2019;3(1):77-103. doi:10.1146/annurev-cancerbio-030518-055653

208. Tata A, Vivier E, Brossay L. Role of the KLRG1 pathway during the immune response to cancer. J Immunol. 2020;204 (1Supplement):88.8.

209. Greenberg SA, Kong SW, Thompson E, Gulla SV. Co-inhibitory T cell receptor KLRG1: human cancer expression and efficacy of neutralization in murine cancer models. Oncotarget. 2019;10 (14):1399-1406. doi:10.18632/oncotarget.26659

210. Tata A, Dodard G, Fugere C, et al. Combination blockade of KLRG1 and PD-1 promotes immune control of local and disseminated cancers. Oncoimmunology. 2021;10(1):1933808. doi:10.1080/2162402X.2021.1933808

211. Cantoni C, Bottino C, Augugliaro R, et al. Molecular and functional characterization of IRp60, a member of the immunoglobulin superfamily that functions as an inhibitory receptor in human NK cells. Eur J Immunol. 1999;29(10):3148-3159. doi:10.1002/(SICI) 1521-4141(199910)29:10<3148::AID-IMMU3148>3.0.CO;2-L

212. Birge RB, Boeltz S, Kumar S, et al. Phosphatidylserine is a global immunosuppressive signal in efferocytosis, infectious disease, and cancer. Cell Death Differ. 2016;23(6):962-978. doi:10.1038/ cdd.2016.11

213. Lankry D, Rovis TL, Jonjic S, Mandelboim O. The interaction between CD300a and phosphatidylserine inhibits tumor cell killing by NK cells. Eur J Immunol. 2013;43(8):2151-2161. doi:10.1002/eji.201343433

214. Simhadri VR, Andersen JF, Calvo E, Choi SC, Coligan JE, Borrego F. Human CD300a binds to phosphatidylethanolamine and phosphatidylserine, and modulates the phagocytosis of dead cells. Blood. 2012;119(12):2799-2809. doi:10.1182/blood-201108-372425

215. Sun X, Huang S, Wang X, Zhang X, Wang X. CD300A promotes tumor progression by PECAM1, ADCY7 and AKT pathway in acute myeloid leukemia. Oncotarget. 2018;9(44):27574-27584. doi:10.18632/oncotarget.24164

216. Jiang L, Xu Y, Zeng X, Fang J, Morse HC, Zhou JX. Suppression of CD300A inhibits the growth of diffuse large B-cell lymphoma. Oncotarget. 2015;6(31):31191-31202. doi:10.18632/ oncotarget.5152
ImmunoTargets and Therapy

\section{Publish your work in this journal}

ImmunoTargets and Therapy is an international, peer-reviewed open access journal focusing on the immunological basis of diseases, potential targets for immune based therapy and treatment protocols employed to improve patient management. Basic immunology and physiology of the immune system in health, and disease will be also covered. In addition, the journal will focus on the impact of management programs and new therapeutic agents and protocols on patient perspectives such as quality of life, adherence and satisfaction. The manuscript management system is completely online and includes a very quick and fair peer-review system, which is all easy to use. Visit http://www.dovepress.com/testimonials.php to read real quotes from published authors. 